University of Nebraska - Lincoln

DigitalCommons@University of Nebraska - Lincoln

Public Access Theses and Dissertations from

Education and Human Sciences, College of

the College of Education and Human Sciences

(CEHS)

7-30-2009

\title{
Improving the Writing Performance of High School Students with Attention Deficit/Hyperactivity Disorder and Writing Difficulties
}

Laura Thompson Jacobson

University of Nebraska - Lincoln, laura.jacobson@huskers.unl.edu

Follow this and additional works at: https://digitalcommons.unl.edu/cehsdiss

Part of the Education Commons

Jacobson, Laura Thompson, "Improving the Writing Performance of High School Students with Attention Deficit/Hyperactivity Disorder and Writing Difficulties" (2009). Public Access Theses and Dissertations from the College of Education and Human Sciences. 45.

https://digitalcommons.unl.edu/cehsdiss/45

This Article is brought to you for free and open access by the Education and Human Sciences, College of (CEHS) at DigitalCommons@University of Nebraska - Lincoln. It has been accepted for inclusion in Public Access Theses and Dissertations from the College of Education and Human Sciences by an authorized administrator of DigitalCommons@University of Nebraska - Lincoln. 


\title{
IMPROVING THE WRITING PERFORMANCE OF HIGH SCHOOL STUDENTS WITH ATTENTION DEFICIT/HYPERACTIVITY DISORDER AND WRITING DIFFICULTIES
}

\author{
By \\ Laura Thompson Jacobson
}

\section{A DISSERTATION}

\author{
Presented to the Faculty of \\ The Graduate College at the University of Nebraska \\ In Partial Fulfillment of Requirements \\ For the Degree of Doctor of Philosophy
}

Major: Educational Studies

Under the Supervision of Professor Robert Reid

Lincoln, Nebraska

July, 2009 
IMPROVING THE WRITING PERFORMANCE OF HIGH SCHOOL STUDENTS WITH ATTENTION DEFICIT/HYPERACTIVITY DISORDER AND WRITING DIFFICULTIES

Laura Thompson Jacobson, Ph.D.

University of Nebraska, 2009

Advisor: Robert Reid

This study examined the effectiveness of persuasive writing instruction using the SelfRegulated Strategy Development (SRSD) model with high school students identified with Attention Deficit/Hyperactivity Disorder (ADHD). Four students in grades 10 and 11 received one-to-one instruction in planning and persuasive essay writing. Instruction had a pronounced positive effect on students' writing. Essays were longer, more complete, and of higher holistic quality. Additional increases were seen in planning time, writing time, and the number of included transitional words and phrases. 
Chapter 1: Introduction........................................... 1

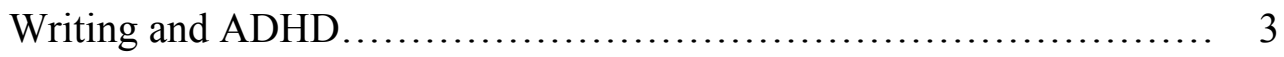

Executive Functioning and ADHD $\ldots \ldots \ldots \ldots \ldots \ldots \ldots \ldots \ldots \ldots \ldots \ldots, 5$

Strategy Use and ADHD..................................... 6

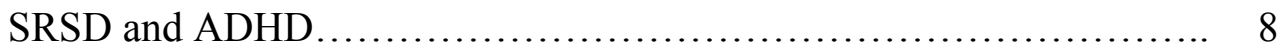

Statement of Purpose......................................... 10

Hypotheses.............................................. 12

Definition of Terms.............................................. 12

Chapter 2: Review of the Literature................................ 14

ADHD Theory..................................................... 17

Writing and ADHD........................................ 23

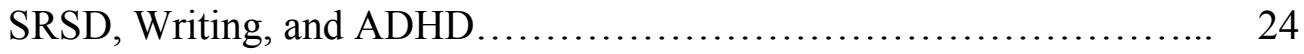

Chapter 3: Method................................................. 29

Experimental Design....................................... 29

Setting.................................................... 29

Participants............................................... 29

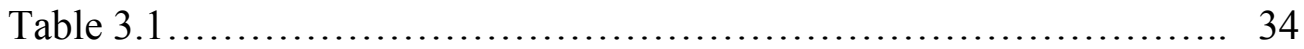

Assessment Measures............................................. 35

Procedures.................................................... 36

Dependent Measures........................................... 37

General Instructional Procedures............................... 39

Instructional Procedures for Teaching the Strategy $\ldots \ldots \ldots \ldots \ldots \ldots \ldots \ldots \ldots 40$ 
Chapter 4: Results................................................... 45

Planning Time............................................. 45

Writing Time............................................... 45

Number of Essay Elements..................................... 46

Number of Words.............................................. 47

Transition Words............................................ 47

Quality ratings............................................. 48

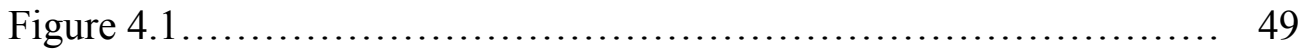

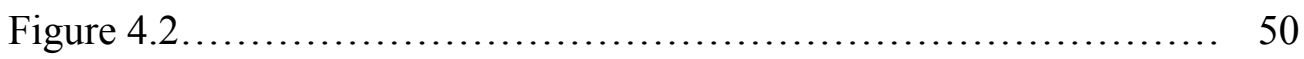

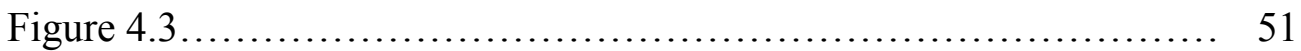

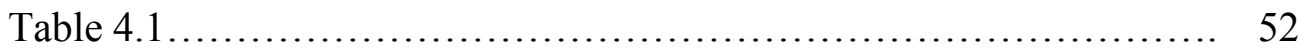

Chapter 5: Discussion........................................... 53

Effects of Dependent Measures ................................ 53

SRSD and Students with ADHD .............................. 57

Limitations and Suggestions for Future Research................... 61

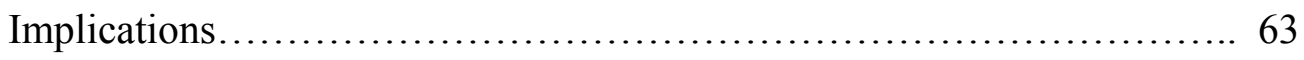

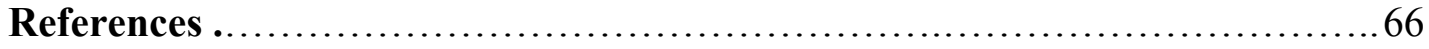

Appendix A: Consent and Assent Forms.............................. 79

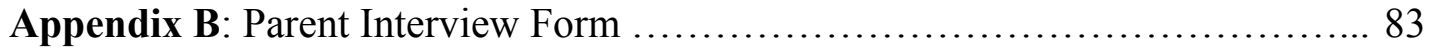

Appendix C: Essay Prompts........................................ 84

Appendix D: Essay Elements Scoring Rubric.......................... 87

Appendix E: Lesson Plans for STOP \& DARE $\ldots \ldots \ldots \ldots \ldots \ldots \ldots \ldots \ldots \ldots \ldots, 88$ 
Appendix F: Lesson Plan Checklists............................... 109

Appendix G: STOP and Dare Graphic Organizer........................ 114

Appendix H: Transition Words and Phrases......................... 115

Appendix I: Graph Templates..................................... 117

Appendix J: Planning Sheet.......................................... 119

Appendix K: Example Student Essays............................... 120 


\section{Chapter 1}

Introduction

Writing is not a simple process. Numerous separate skills must be employed to produce an effective piece of text. The writer must first learn not only the necessary mechanics but also appropriate composition skills (Graham \& Harris, 2003). To write effectively an author must be able to create and execute a plan for writing that includes, generating content, organizing ideas and text, addressing the appropriate audience, and revising and improving her work. These skills require attention to task and selfmonitoring throughout the writing process (Harris, Graham, \& Mason, 2003). Each of these skills requires extensive practice for mastery, and current data suggests that American students are not effectively developing these skills.

The National Assessment of Educational Progress has released a series of reports depicting American students as performing poorly in the area of writing. Nearly $75 \%$ of participating high school students were unable to meet the requirements for the proficient standard. Of those students identified as having special needs, $95 \%$ were at or below the basic level for writing performance (National Assessment of Educational Progress, 2008). While not new, the concerns surrounding the writing skills of American students may be more pressing today than at any other time in history. The economic shift towards service industries means effective writing skills are necessary for greater numbers of American graduates (College Entrance Examination Board, 2004; National Center for Education Statistics, 1998). Most corporations are expecting most hourly employees and nearly all salaried employees are to have some writing responsibilities (College Entrance Examination Board, 2004). In addition to workplace requirements, the number of states 
and school districts requiring exit examinations to meet federal requirements continues to increase. By 2012, 72\% of high school students are predicted to be in schools requiring exit exams (Achieve, 2006; Center on Education Policy, 2007). Currently, specific writing abilities must be demonstrated by students in 15 states (Center on Education Policy, 2007; Achieve, 2006).

Exit and demonstration exams are frequently difficult for students with disabilities. For example, in Arizona in 2007, only $30 \%$ of students with disabilities were able to pass the states' writing examination on the first try (grade 10 ). By $12^{\text {th }}$ grade, $62 \%$ of students with disabilities were still unable to pass the writing exam, compared to $17 \%$ of all students (Center on Education Policy, 2008). In Maryland, substantial increases have been seen in the number of students passing the English exit exam, which includes a writing component. However, while the overall percentage of students passing has increased from $70.9 \%$ in 2006 to $80 \%$ in 2008 , the percentage of students with disabilities passing the exam remains at 39\% (Center on Education Policy, 2008). Similarly, in Arizona, $83 \%$ of the all students were able to pass the state's writing exam by twelfth grade, a $10 \%$ increase from those passing in their first try. Yet, only $38 \%$ of students with disabilities successfully passed the writing test by grade 12 (Center on Education Policy, 2008). Based on the national and statewide data, it appears that the high-stakes testing movement may increase the barriers placed before students with disabilities, making a diploma more difficult to attain. Additionally, obtaining post-secondary employment outside of entry-level positions and/or getting into college may be difficult.

Clearly, many American high school students lack effective writing skills, however, no clear explanation for these deficits is evident. One element of the problem 
may be how much writing is taught in American classrooms. The amount of writing instruction is not keeping up with expectations of college and the work place. Applebee and Langer (2006) reported that $40 \%$ of high school students could not recall being required to write a paper of three or more pages. Writing is rarely required outside the English classroom and most students report that any writing they are assigned requires less than one hour a week (Applebee \& Langer, 2006). Writing is clearly not receiving the same level of attention allocated to other core academic skills. Writing's lack of prominence is likely to have future negative influence. Nearly $35 \%$ of college students report there are gaps between their level of preparation and the quality of writing that is expected, and 9\% consider the gaps large (Peter D. Hart Research Associates, 2005). High school graduates report similar skill gaps. Consequently, many graduates of American high schools may be ill-equipped to do the writing expected of them. Writing and ADHD

One group that may be at-risk for writing problems is students with ADHD. ADHD is one of the most frequently diagnosed disorders of childhood (Barkley, 2006), affecting nearly two million school-aged children (Forness \& Kavale, 2002). Students with ADHD often struggle in school. They are more likely to have failing grades (Fergusson, Horwood, \& Lynskey, 1993) and lower achievement test scores than their non-disabled peers (Carlson \& Tamm, 2000; Frankenberger \& Connon, 1999). Additionally, drop out, expulsion, and grade repetition rates are higher for students with ADHD (Barkley, 1998; Weiss \& Hechtmann, 1993). Moreover, 20 to $40 \%$ of these students also have learning disabilities (LD), putting them at increased risk for academic problems (Barkley, 1998). Deficits in prerequisite skills such as spelling (MTA 
Cooperative Group, 1999) are well established in the literature. Students with ADHD may also struggle to use language effectively to express ideas or create coherent compositions (Purvis \& Tannock, 1997; Tannock, Purvis \& Schachar, 1993; Tannock \& Schachar, 1996).

There is little research examining the writing skills of students with ADHD but available studies suggest that writing, like many academic skills, may be difficult for these learners. In a comparative study of students with a diagnosis of LD, ADHD, comorbid LD and ADHD, and no disability, Mayes, Calhoun, and Crowell (2000) found $65.1 \%$ of the students with ADHD demonstrated significant problems with written expression. Re, Pedron, and Cornoldi (2007), examined the expressive writing skills of students exhibiting ADHD symptoms. They found students with ADHD symptoms wrote compositions that were substantially shorter with more errors than controls. Additionally, the writing quality of students with ADHD symptoms was significantly poorer than controls, evidenced by greater numbers of repetitions in text, lower numbers of adjectives, and fewer subordinate clauses (Re, Pedron, \& Cornoldi, 2007). Resta and Eliot (1994) examined the writing of 21 clinic-referred boys with ADHD. Compositions of the students identified as having ADHD scored significantly below controls in general writing ability, word complexity, and productivity. In a study of the expository writing of middle school students that included two students with ADHD, De La Paz (2001) reported that ADHD students, on average, wrote short essays of low quality and frequently omitted essential essay elements (De La Paz, 2001). Lienemann and Reid (2008) also examined expository writing. In their study elementary school students with ADHD, wrote essays that were short, included few essay elements, and were of low 
quality, even though two of the students had received previous instruction in narrative writing. Reid and Lienemann (2006) found that three elementary school students with ADHD had similar problems with story writing.

Executive Functioning and ADHD

The writing difficulties of students with ADHD may be caused by problems with executive functioning. Current theory suggests that deficits in the development of behavioral inhibition impair the executive functioning of individuals with ADHD (Barkley, 1997). These deficits influence the effectiveness of four executive functions (EF): nonverbal working memory; internalization of speech; self-regulation; and planning or reconstitution (the ability to analyze and recombine behavior to create multiple novel responses for the attainment of a goal) (Barkley, 2006). Explained briefly, behavioral inhibition is made up of three process: (1) inhibition of the initial prepotent response to an event; (2) stopping of a response, allowing a delay in the decision to respond; and (3) protection of this delay period and the self-direction that takes place within it, from internal or external interference. Behavioral inhibition allows for the performance of the four executive functions. Executive functions allow one's attention to be focused on an activity without interference from distracting stimuli. By addressing received or internal instructions rather than external influences, the EFs allow for inhibition of impulses and self-regulation of behavior (Messina, Tiedemann, Andrade, \& Primi, 2006). The internal regulation of behavior stemming from the EFs and behavioral inhibition allows for the performance of goal-directed actions, and the creation of novel sequences of self-created, goal-directed responses. Together the process creates persistence toward a goal, allowing for identification of errors and the ability to re-start the sequence when interruptions arise 
(Barkley, 2006). For individuals with ADHD, the deficits in behavioral inhibition may interrupt the execution of EFs, decreasing the individual's ability to self-regulate (Barkely, 2006). Behaviors frequently seen in students with ADHD, such as difficulties completing a task, maintaining a schedule, or meeting deadlines, are essentially EF problems. These behaviors illustrate the disruption of self-control and goal-directed behaviors, and are controlled by the immediate environment and/or internal stimulus and its consequences, rather than internally (Barkley, 1997).

Research has shown that such EF impairments negatively affect academic functioning in students with ADHD (Clark, Prior, \& Kinsella, 2002). Given these issues, the demands of planning, organization, and attention required for the writing process, may be overwhelming for a student with ADHD. Learning these skills may be further inhibited by difficulties with successfully imitating the behavior of others or applying information learned through observation (Barkley, 1997), as is expected in a classroom environment. Students with ADHD also have difficulty self-regulating their behavior, motivation, or thought (Barkley, 2006), which may make planning and executing a writing task difficult. Furthermore, these individuals may exhibit difficulties sustaining self-motivation and/or dependence on externally provided consequences. Students with ADHD often have difficulty persisting in a task, setting or engaging in goal-directed behaviors without the presence of external reinforcement, all of which are self-regulatory in nature (Barkley, 2006) and required by the writing process.

Strategy Use and ADHD

Another problem for students with ADHD is strategy use. Research suggests that students with ADHD may have difficulties identifying or creating appropriate strategies 
for given tasks. For example, in their 1982 study, Tant and Douglas found that students with ADHD were significantly less effective problem-solvers than children in either of the other groups (e.g., asked more questions). The authors suggest that these difficulties illustrate not a difficulty with strategy implementation, but a pool of less effective strategies to pull from than that of controls. The authors also propose that the development of effective strategies for the mastery of complex material may be inhibited in students with ADHD (Tant \& Douglas, 1982). Similarly, Hamlett, Pelligrini, and Conners (1987), found that students with ADHD were less aware of effective problemsolving strategies, and likely less able to generate and use such strategies for problem solving. Additionally, they appeared less aware of the purpose and use of strategies and self-monitoring of performance. Boys with ADHD have also demonstrated less effective and less effortful use of study strategies when compared to controls, and, when provided with a list, were less apt to identify the "best" strategies (O’Neill \& Douglas, 1991). This suggests that the strategy problems exhibited by students with ADHD may not be related to a lack of knowledge of strategies, but perhaps a failure to employ the necessary strategies or put forth the effort required to execute them (O’Neill \& Douglas, 1991). Supporting these ideas, O’Neil and Douglas (1996) found that boys with ADHD employed strategies that were less organized and less effortful than those in the nondisabled control group. Though able to identify effective strategies from a provided list, their rapid, basically effortless practice style, and inferior recall, illustrated how little those identified strategies were put into use (O’Neill \& Douglas, 1996). The lack of effortful and effective execution or creation of strategies for problem-solving presented in these studies and others (e.g., Benezra \& Douglas, 1988; Cornoldi, Barbieri, Gaiani, \& 
Zocchi, 1999; Purvis \& Tannock, 1997; Waschbusch, Craig, Pelham, \& King, 2007), suggests that instruction in specific strategy instruction may be appropriate for students with ADHD.

\section{SRSD and ADHD}

If left unaddressed, these writing problems have immediate academic consequences and are likely to cause future problems as students enter adulthood. Addressing the needs of these students with scientifically based instructional methods, before they face stiff graduation requirements, course failure, the SAT, and/or postsecondary school or employment, may improve the writing of these students. One approach that could be used to improve the writing skills of students with ADHD is through strategy instruction using the Self-Regulated Strategy Development (SRSD) model (Harris \& Graham, 1996). The model has been widely used to teach writing skills, and has been found to be a powerful instructional tool (Graham \& Harris, 2003). In a meta-analysis of single subject writing intervention research, Rogers and Graham (2008) found strategy instruction in planning/drafting of narrative and expository text, following the SRSD model, to be highly effective. Not only were the effects immediate but also maintained over time, and were generalized to untaught genres (Rogers \& Graham, 2008). These results are similar to other meta-analyses examining writing instruction and the SRSD model (Graham \& Perin, 2006; Graham \& Harris, 2003).

The SRSD model addresses these deficits in executive functioning and the strategy use in four ways. First, the model addresses the working memory deficits that are common in students with ADHD. The explicit instruction of academic strategies reduces the demands placed on working memory by teaching to automaticity, and scaffolding 
practice with prompts, cues, and organizers (Lienemann \& Reid, 2008). Second, students with ADHD sometimes do not have useful strategies in their repertoire. By explicitly teaching strategies to mastery, students are able to develop a collection of effective strategies for addressing frequent academic tasks. Third, self-regulation strategies are explicitly taught. Current theories of ADHD emphasize that deficits in self-regulation are the basis for ADHD (Barkley, 1997). Instruction in self-regulation strategies has been shown to be effective in improving maintenance of effort and focus (Reid, Trout, \& Schartz, 2005), areas where students with ADHD frequently struggle. Finally, students with ADHD frequently struggle with strategic planning and goal setting (Barkley, 1997; Kliegel, Ropeter, \& Mackinlay, 2006). Difficulties establishing goals, holding goals in mind, and directing behaviors to achieve set goals are common among individuals with ADHD. To address these difficulties, the importance of goals is discussed and progress toward student goals is clearly monitored throughout instruction. This helps the student with ADHD understand the need for a goal, see progress toward it, and keep the target goal in mind.

There is a limited body of research available that supports the use of strategy instruction following the SRSD model with students with ADHD. Reid and Lienemann (2006) examined the effectiveness of a narrative writing strategy with three elementary students with ADHD. Following instruction, all participants produced longer, higher quality stories, and those results were generally maintained over time. Similarly, Lienemann, Graham, Leader-Janssen and Reid (2006) found that narrative writing improved following instruction. Increases were seen in story length, number of included story elements, and holistic quality, and were maintained at follow-up. Lienemann and 
Reid (2008) examined the effects of SRSD on the expository writing of four fourth- and fifth-grade students with ADHD. Results indicated instruction had a positive over all effect on the students' writing, including length, completeness, and holistic quality. Finally, in the only study focusing on adolescents, De La Paz (2001) examined the impact of SRSD on expository writing of two middle school students with ADHD. De La Paz found substantial increases in the use of planning, essay length, and holistic quality (De La Paz, 2001).

Research suggests that strategy instruction following the SRSD model is an effective method for improving the writing of elementary and adolescent students with ADHD. However, the effectiveness of its use with high school students with ADHD has not been addressed. In the pilot for this study, Jacobson \& Reid, (2008) provided instruction in persuasive essay writing to three high school students with ADHD. All three students improved over baseline performance on all dependent variables (planning time, number of transition words included, number of essay parts, length, and essay quality). Improved performance levels remained at the three-week follow-up, though at lower levels than in independent performance.

\section{Statement of Purpose}

The purpose of this study was to replicate and extend the pilot in four areas. First, additional student information was gathered. The pilot study relied on parent interviews and file reviews for student data. Two measures were added: (1) The ADHD Rating Scale-IV (DuPaul, Power, Anastopoulos, \& Reid, 1998) was used as additional validation of the ADHD diagnosis and (2) the persuasive essay writing portion of the Written Expression subtest of the Wechsler Individual Achievement Test II (WIAT-II; 
Psychological Corp., 2001) provided for support the presence of writing difficulties. Second, data on time spent writing were included in this study. The pilot failed to examine the effect of strategy instruction on the amount of time spent writing. This information was gathered to examine whether increases in time spent writing correspond with increases in other measured areas as well. Third, extensions were made in the area of instruction. Students received instruction in paragraph writing and essay organization not included in the previous study. Specifically, students learned how to organize an effective introductory paragraph and how to link supporting paragraphs back to the ideas proposed in the introduction. Additionally, students received explicit instruction in the purpose and use of transitional words and phrases. Though introduced and measured in the pilot, no explicit instruction in their use was provided. In the previous study, improvements were seen across all measures but those improvements were least dramatic in the area of quality. The purpose of these instructional changes was to improve the quality of the students' essays. By increasing the amount instruction in essay format and paragraph organization the hope was that further increases in quality would be seen. Fourth, additional maintenance data were gathered. In the pilot study, the only maintenance probe was taken three weeks after independent performance, making it impossible to determine the presence of any long-term effects. In this study, students were asked to write two essays two and four weeks after independent performance. Longterm strategy maintenance is a concern for students with ADHD. Having multiple data points, after instruction, provides a clearer picture of each student's maintenance of the strategies. 
Hypotheses

The hypotheses were that as a result of instruction, (a) students would spend more time planning (b) students would spend more time writing each essay, (c) more essay elements would be included, (d), students would write longer essays, (e) more transition words would be included, and (f) the holistic quality of student essays would improve. Definition of Terms

Attention Deficit/Hyperactivity Disorder (ADHD). The Diagnostic and Statistical Manual of Mental Disorders Fourth Edition Text Revision (DSM-IV-TR: American Psychiatric Association, 2000) the critical aspect of ADHD is a "persistent pattern of inattention and/or hyperactivity-impulsivity that is more frequently displayed and more severe than is typically observed in individuals at a comparable level of development (p.85)." There are three subtypes of ADHD: (1) Combined Type, (2) Predominantly Inattentive, and (3) Predominantly Hyperactive-Impulsive Type. To meet the criteria of any subtype, the symptoms must be evident before age seven, persist for at least six months, and be considered maladaptive and developmentally inappropriate, given the child's age (Campbell, 2000). Additionally, the behaviors and characteristics cannot be associated exclusively or more closely with a Psychotic Disorder, Persuasive Developmental Disorder, Schizophrenia, or other mental disorder (American Psychiatric Association, 2000).

Executive Function. Executive functions (EF) are neurocognitive processes that assist in task representation, planning, execution, and evaluation (Zelazo \& Jacques, 1997). 
Expository Text. The purpose of expository text is to inform, explain, describe, persuade, or present information. Generally, expository text is subject-specific and factbased. The organization of an expository piece of writing is dependent upon its genre (Englert \& Mariage, 1991).

Persuasive Text. In persuasive writing, the author must take a particular point of view and attempt to convince the reader to adopt the same perspective. The production of persuasive text that is clear, convincing, appropriately sequenced, and addressing views from both sides of the argument is challenging for developing writers (Nippold, WardLongergan, \& Fanning, 2005).

Self-Regulation. A self-directive, continuous process during which, the individual monitors progress, checks outcomes, and redirects unsuccessful efforts (Berk, 2003). Through this process learners convert their mental abilities into task-specific academic skills (Zimmerman, 2001).

Strategy. A strategy is a series of sequential steps that allow a student to perform a task (Reid \& Lienemann, 2006a). A strategy is multi-faceted; its use should improve performance on academic tasks by enhancing and focusing the student's effort. 


\section{Chapter 2}

Review of the Literature

Writing is neither easy nor innate. Many students struggle in their efforts to create effective text. The strategies required to set goals, produce text, or engage in the writing process may not have been learned and may not be available in their repertoire. Additionally, the effective use and management of necessary strategies may pose further difficulties for student writers (De La Paz, Swanson, \& Graham, 1998; Graham \& Harris, 2000; Harris \& Graham, 1999). Unlike strong or experienced writers who routinely use planning and goal-setting strategies, students who struggle with writing are more likely to translate a writing task into an opportunity for knowledge telling. That is, any information about the given topic will be written down, little or no planning may take place prior to writing, and little attention may be paid to generating content or meeting assignment requirements (Graham, 1990). This process minimizes the need for selfregulatory strategies, instead focusing on the immediate retrieval of information for use in the task (Graham \& Harris, 1997). After producing such text, novice or less competent writers are unlikely to re-address the content through revisions instead focusing on mechanical errors (MacArthur \& Graham, 1987; MacArthur, Graham, \& Schwartz, 1995; Scardamalia \& Bereiter, 1986). As such, the revisions often result in few improvements in the quality of the students' writing (Graham, MacArthur, \& Schwartz, 1995; Scardamalia \& Bereiter, 1986). Consequently, these skill or strategy deficits, combined with limited knowledge of genre or audience and persistence problems, may hinder students' writing quality (Graham \& Harris, 2005). 
Addressing the needs of struggling student writers with scientifically based instructional methods, may help improve the writing of these students. One approach is through strategy instruction using the SRSD model (Harris \& Graham, 1996). The major goals of SRSD are 1) student mastery of the higher-level cognitive processes used in writing; 2) development of independent reflection and self-regulation of strategy used while writing; and 3) development of positive attitudes about writing (Graham \& Harris, 1993). SRSD consists of six stages, each rooted in instructional theory. These stages may be reordered, combined, or even in some cases omitted. By moving through each stage, SRSD promotes the explicit instruction of writing skills, processes, or knowledge, with the goal of student mastery and independent use of the strategy (Graham \& Perin, 2007). During instruction teachers using the SRSD model provide think-aloud demonstrations, which provide examples of how effective writers move through the writing process, selfregulate, and problem solve. In addition, although writing is initially collaborative and teacher-led, scaffolded supports are gradually faded to promote students' independent use of the strategies. Finally, mnemonic devices are used to help students remember the steps and sequence for independently completing the strategy (De La Paz, 2007).

The model has been widely used to teach writing skills and instruction, and has been found to be a powerful instructional tool (Graham \& Harris, 2003). In a metaanalysis of 88 single-subject writing intervention studies, Rogers and Graham (2008) found strategy instruction in planning/drafting of narrative and expository text, following the SRSD model (25 studies), to be highly effective. The most common outcome measure in these studies was elements, or the structural components required by the genre of the assigned composition. Overall the mean percent non-overlapping data (PND) for genre 
elements was $96 \%$ after treatment and $90 \%$ at maintenance, three weeks or more postinstruction. According to Scruggs, Mastropieri, Cook, and Escobar (1986), PND greater than $90 \%$ can be interpreted as a highly effective treatment. Additionally, planning strategy instruction generalized to untaught genres (mean PND $=85 \%$ ). Comparably strong results were found for productivity (e.g., number of words, number of sentences) and writing quality. The mean PND after instruction was $91 \%$ and $99 \%$ respectively. Additionally, gains in productivity were largely maintained over time (mean PND = $86 \%$ ). Of particular importance was the finding that the mean PND for those studies examining expository writing (the authors combined expository and persuasive genres) was $94 \%$ after treatment and $89 \%$ at maintenance, indicating a highly effective treatment for this genre.

Strategy instruction using the SRSD model has been an effective instructional tool for improving the writing (expository and narrative) of adolescents both with and without disabilities. In their meta-analysis of adolescent writing instruction (123 studies), Graham and Perin (2007) reported that strategy instruction was one of the most powerful techniques for improving the quality of adolescent student writing. Strategy instruction in planning and/or revising was found to be a highly effective treatment. The overall mean effect size for all studies was 1.03 indicating a large effect (20 studies). Even stronger results were found for those studies using the SRSD model (eight studies) where the mean effect size was 1.15 . Of particular importance were the findings dealing specifically with expository writing. For studies specifically addressing expository (including persuasive) writing the mean effect size was 1.04 , indicating that this type of instruction has a strong treatment effect (Graham \& Perin, 2007). This is particularly important since 
this study addressed expository writing with adolescents. The instruction and supports provided are especially useful to students who have disabilities or otherwise struggle with writing.

ADHD Theory

Children with ADHD frequently struggle with academics, and these difficulties have been found to continue through adolescence (Frazier, Youngstrom, Glutting, \& Watkins, 2007). Current ADHD theory suggests that one basis for the academic difficulties of students with ADHD may be problems with strategy acquisition and execution (Barkley, 2006). According to this theory, behavior inhibition deficits influence the effectiveness of the executive functions needed to write effectively (i.e., planning, self-regulation, and non-verbal working memory). Support for this theory is found throughout the research literature. Tant and Douglas (1982) suggested that the development of problem solving strategies might be hindered by the attentional difficulties of students with ADHD. They found that the students with ADHD were less efficient problem solvers and used fewer problem-solving strategies to create questions. Additionally, the students with ADHD were less able to verbalize the elements of a strategy. The authors suggested that the issues with strategy implementation lie not with a failure to implement strategies that the students already have in their repertoire, but that the strategies that the students with ADHD already had available to them were less effective.

Students with ADHD have also been found to be seemingly less aware of effective problem solving strategies than their non-disabled peers (Hamlett, Pellegrini, and Conners, 1987). Researchers asked students with and without ADHD to perform a 
memory task that required organization and self-monitoring in order to examine differences in the groups' strategic problem solving. Results revealed consistent and significant deficiencies in executive processing, similar to those seen in previous research. Students in the control group were more likely to generate and employ strategies spontaneously than students with ADHD. Additionally, as in Tant and Douglas (1982) the explanations and instructions presented by the ADHD group were less effective than those provided by controls. Namely, their responses included less information and showed less awareness of the makeup and use of strategies and selfmonitoring necessary for the task.

Similarly, in their 1991 study, O'Neill and Douglas examined the function of metacognition and executive processes in the use of study strategies in boys with ADHD, compared to those with reading disabilities (RD) and controls. The results showed that there was no significant difference in the responses of each group when interviewed about the types of strategies that would be needed to perform the task, or the amount of effort the task would require. However, when asked to actually execute the study task clear differences were found between the ADHD group and the RD and control groups. Boys with ADHD spent less time studying for the recall task and were more likely to use skimming, one of the least powerful strategies available, to study for the task. Moreover, when presented with a list of strategy options, the boys in the ADHD group were less likely to choose the strategies identified as the "best." Overall, although they identified potential strategies and effort requirements for a given task as well as the control group, deficits were seen in the selection, manipulation, and execution of study strategies. This results was in line with previous research that has suggested that individuals with ADHD 
are able to execute memory and learning tasks as well as normal controls where strategic effort is not required. However, when the task demands strategic effort deficits are clear. The results suggested that though students with ADHD may be aware of strategies that will be effective in performing the task, they might not choose to use them. The authors suggest that result may reflect a lack of mastery of necessary skills or a lack of conviction that the task is important enough to expend the effort necessary to perform it $\left(\mathrm{O}^{\prime} \mathrm{Neill} \&\right.$ Douglas, 1991).

Ineffective strategy selections by students with ADHD were also seen in O'Neill and Douglas's 1996 study. Although the boys with ADHD did identify examples of effective strategies, few actually employed strategies with these characteristics. Given a list-learning task, the boys with ADHD were more likely to rely on rote repetition of single items and spent less time rehearsing than those in the control group. The poorer recall of the students with ADHD was a reflection of these less-effortful and less effective strategy selections.

Using a modified version of the Six Element Test (SET), Skilos and Kerns (2004) also examined the strategy use of children with ADHD. Successful performance of the tasks requires students to plan how they will execute the task, monitor their behavior, and keep track of passing time. Overall, students with ADHD performed more poorly on the SET than controls, attempting significantly fewer tasks and monitoring the time far less frequently. The authors propose that these results imply that children with ADHD were significantly less able to plan, organize their behavior, problem-solve, and monitor their performance than controls. 
Shallice, Marzocchi, Cosner, Del Savio, Meuter, and Rumiati (2002), also found strategy deficits in students with ADHD. After completing the Hayling Sentence Completion task, only $9.5 \%$ of students with ADHD reported the use of a strategy, compared to $47 \%$ of those in the control group. The task requires students to complete a sentence first with a word that fits the context of the sentence and then later with a word that does not makes sense in the sentence. After the task was completed the children were asked how they had carried out the task. Those students with ADHD, who reported using a strategy to produce words, were less likely to use the concrete strategy of looking around the room for objects that could be used in the sentences reported by controls. Significant strategy deficits were also found in students with ADHD using the Iowa Gambling task (Toplak, Jain, \& Tannock, 2005). The task is designed to reproduce the uncertainties of real-life decision-making, including rewards and penalties based on those choices. Students are asked to select cards from four decks, of which (unbeknownst to the participants) two are disadvantageous (high gains and high losses) and two are advantageous (low gains and low loses). Results showed that though most of the students with ADHD realized that the decks were either advantageous or disadvantageous, they chose more cards from the least profitable deck, and fewer from the profitable decks than controls. These findings suggest that the students with ADHD frequently failed to spontaneously develop or use an efficient strategy for tracking card value or penalties, or to regulate their behavior through the task.

Cornoldi, Barbieri, Gaiani, and Zocchi (1999) conducted a systematic series of research studies examining the strategic organizational memory of students with ADHD. In three studies, the metacognitive and strategic memory of children with ADHD were 
compared to non-disabled control children. In the first study, the authors explored whether children with ADHD had difficulties with a strategic organization task and whether any deficit found was caused by deficits in metacognitive knowledge. The configuration of the tasks required the student to spontaneously develop a strategic method, taking into account changes in the organization of the material. Students with ADHD scored more poorly than the controls, with higher numbers of intrusions and remembered fewer items from the lists that were adjacent to one another, signifying inefficient use of strategic memory. In the second study, a new explicit instruction condition was introduced. Participants were instructed in a clustering strategy and assisted in using it. As in the first study, students were initially directed to the task without instruction in the strategy. In the second phase, students were instructed in and directed to use the strategy. Results from the first phase mirrored those of the first study, with students with ADHD performing more poorly and having greater numbers of intrusions than control students. However, results from the second phase showed marked differences. After instruction in the clustering strategy the children with ADHD were able to improve recall performance scores and the number of intrusion decreased dramatically. The students with ADHD were able to use the organizational memory strategy in the same way as controls when first provided with adequate instruction. According to the authors, these results suggested that the strategy problems seen in individuals with ADHD are not related to memory problems or inability, but to a less spontaneous use of the strategy.

In the final study, the authors examined whether the strategic memory deficits in the students with ADHD were due to deficits in metacognitive knowledge (i.e, not 
knowing what strategy to use) or due to an inability to use that knowledge. Results supported the idea that for students with ADHD, knowledge of an appropriate strategy does not mean that that strategy will be used. When the use of a strategy was demonstrated, immediate improvements were seen in the performance of members of the control group. While the strategy did improve the performance of students with ADHD, decreasing the number of intrusions and the difference between group performance levels, these changes were not maintained in further trials. In trials three and four, before which students were reminded they could use the strategy, the difference in recall performance between the groups dropped substantially. Deficits in the efficient use and/or mastery of strategies by students with ADHD were clearly evidenced in the results of the study. Additionally, it is important to emphasize the substantial performance increases made by the students with ADHD when instructed in the use of an effective strategy. These improvements matched that of controls, suggesting the affect of strategy instruction on the learning of students with ADHD.

Finally, Kofman, Larson, and Mostofsky (2008) examined the strategic planning skills of students with ADHD. Students were required to consistently use a simple testtaking strategy to earn points. In the initial trial students were told that the problems in the box were worth 10 points and those outside the box were worth 1 point. Students were then directed to complete as many problems as possible to earn the maximum amount of points in the give amount of time. In the second trial, students were informed of the most efficient strategy for earning points, then were asked to repeat the instructions back to the researchers to ensure understanding before beginning the task again. Results found that few students spontaneously used the strategy in the first trial. After specific 
strategy instruction, performance improved in both ADHD and control groups. However, even after controlling for IQ or numbers of problems solved students with ADHD scored fewer points and solved fewer high-point problems than controls. The poorer performance of students with ADHD was likely related to their inconsistent strategy use. Significantly fewer students with ADHD showed evidence of using the strategy, and those that started out using the strategy were more likely to discontinue its use as they progressed through the task, even when the strategy was clearly understood.

Writing and ADHD

There is little research examining the writing skills of students with ADHD. In a comparative study of students with a diagnosis of LD, ADHD, co-morbid LD and ADHD, and no disability, Mayes, Calhoun, and Crowell (2000) found 65.1\% of the students with ADHD demonstrated significant problems with written expression. Re, Pedron, and Cornoldi (2007) examined the expressive writing skills of students for three age groups exhibiting ADHD symptoms. In each of three studies, children with ADHD symptoms and control children were matched for gender, age, schooling, estimated IQ, rated ability, and SES. In the first study the authors examined the expressive writing, spelling and writing speed of students with ADHD compared to controls. They found students with ADHD symptoms wrote shorter, more error filled compositions than controls. Specifically, students with ADHD scored significantly lower on adequacy (i.e., satisfactorily written with respect to the task request), structure (text organization), lexicon (quantity of different words used), and grammar. Students with ADHD also wrote significantly fewer words, on average, than controls. Additionally, students with ADHD symptoms wrote poorer quality compositions, including frequent repetitions and few 
descriptive words and phrases. Finally, the ADHD group made more than four times the number of errors than the control group, with a mean percentage of errors greater than 7 percent.

Study two examined the expressive writing of students with ADHD versus controls when presented with a verbal prompt versus an image. Many of the results of the second study mirrored those found in study one. Students with ADHD continued to write significantly shorter compositions, of lower overall quality and with more errors than controls. However, when presented with a verbal scaffold, they included significantly more qualitative adjectives compared to the image condition. Additionally, they made a greater number of repetitions (though not statistically significant) in the image condition than when provided with the verbal scaffold. In the final study, students were presented with a series of images forming a short story and were asked to write a narrative text based on the images. As in the previous studies, the students with ADHD performed significantly lower on all qualitative measures than controls. Likewise, Resta \& Eliot (1994) reported that boys with ADHD scored significantly below controls in general writing ability, word complexity, and productivity. Studies have also found that students with ADHD, generally write short essays, of low quality, and frequently omit essential essay elements (De La Paz, 2001, Lienemann \& Reid, 2008). Similar problems with story writing have been found in elementary school students with ADHD (Reid \& Lienemann, 2006a).

SRSD, Writing, and ADHD

A small but growing literature base suggests that strategy instruction using SRSD is effective with students with ADHD. The SRSD model directly addresses the learning 
needs of students with ADHD in the following ways: 1) the importance of goals is discussed and progress toward student goals is clearly monitored, 2) self-regulation strategies, which have demonstrated the capacity to have an effect on the improvement of ability and maintenance of effort (Reid, Trout, \& Schartz, 2005), are explicitly developed, and 3) the model reduces the demands placed on working memory by teaching to automaticity, and scaffolding practice with prompts, cues and organizers (Lienemann \& Reid, 2008). SRSD has been found to have greater treatment effects than all other forms of strategy instruction combined (Graham, 2006). Its components, taught in the systematic, scripted manner of the SRSD model, address many of the welldocumented learning need of students with writing disabilities.

Reid and Lienemann (2006) examined the effectiveness of a narrative writing strategy with three elementary students with ADHD. Prior to instruction, the students produced stories that were inconsistent in their inclusion of necessary essay parts, short, and of poor quality. At baseline the overall mean number of story parts for the three students was 3.33 out of seven available. At baseline, students wrote an average of 34.67 words that were received an average score of 1.53 on holistic quality. Following instruction using the SRSD model, writing performance stabilized and each participant produced stories that included the necessary components $(\mathrm{m}=7 ; \mathrm{PND}=100 \%)$, were longer $(\mathrm{m}=151.33 ; \mathrm{PND}=100 \%)$, and of higher quality $(\mathrm{m}=4.27)$ than those at baseline. Moreover, these results were generally maintained over time $(\mathrm{PND}=100 \%)$.

Lienemann, Graham, Leader-Janssen, and Reid (2006) examined the narrative writing of struggling second graders. One participant, Sarah, was identified as having ADHD, as well as other co-morbid disabilities. At baseline, Sarah's mean story length 
was 48.3 words, with an average of two included story elements. After narrative writing instruction using the SRSD model Sarah's story writing improved in all measured areas. At independent performance she wrote 82 words and maintained her performance above baseline at the follow-up writing a story with 72 words. She also was able to include more essay elements at independent performance $(\mathrm{m}=5.3)$ and maintenance (5). Finally, Sarah's holistic quality scores also improved from a mean of 2.7 at baseline to 3.7 and 3 at independent performance and maintenance, respectively.

Lienemann and Reid (2008) examined the effects of SRSD on the expository writing of four fourth- and fifth-grade students with ADHD. As in the previous study, students' compositions were generally short $(\mathrm{m}=24.5)$, lacking necessary elements $(\mathrm{m}=2.15)$, and of poor quality $(\mathrm{m}=1.45)$. Results indicated instruction stabilized performance and had a positive over all effect on the students' writing, including length $(\mathrm{m}=102.25 ; \mathrm{PND}=100 \%)$, completeness $(\mathrm{m}=9.34 ; \mathrm{PND}=100 \%)$, and holistic quality $(m=4.98)$. Again, these results were maintained at the follow-up. Similar results were found in one of the only study focusing on adolescents.

De La Paz (2001) examined the impact of SRSD on expository writing of two middle school students with ADHD. De La Paz found substantial increases in the measured variables. At baseline, the mean score for student planning was 0.1 . After instruction students' plans scored an average of four out of six at both post instruction and maintenance. Students' essay length also increased after instruction from an average of 90.45 words at baseline to 173.85 immediately following instruction and 145 at follow up. The number of included elements also improved over baseline levels (PND 100\%), as 
did the holistic quality of students' essays (from $\mathrm{m}=2.1$ to $\mathrm{m}=4.65,4$ at independent performance and maintenance respectively) (De La Paz, 2001).

Finally, Jacobson and Reid (in press) reported that after persuasive essay writing instruction using the SRSD model, three high school students with ADHD improved on all measured variables. At baseline students produced essays with an average of 3.36 essay elements, 106.67 words, and an average holistic quality of 1.74. Additionally, students planned for an average of 0 minutes, and used .72 transition words in each essay. In the independent performance phase, students wrote essays that were longer $(\mathrm{m}=225.17 ; \mathrm{PND}=100 \%)$, included more necessary essay elements $(\mathrm{m}=6.33 ;$ PND $100 \%)$, and were of higher quality $(\mathrm{m}=4.77$; PND $=100 \%)$. Additionally, students spent more time planning prior to writing $(\mathrm{m}=30.43$ minutes $)$ and included more transition words $(\mathrm{m}=4.77)$ in their essays. Improvements continued in maintenance with length $(m=173.67 ; \mathrm{PND}=66.7 \%)$, essay parts $(\mathrm{m}=5.67 ; \mathrm{PND}=100 \%)$, and quality $(\mathrm{m}=2.67$; $\mathrm{PND}=66.7 \%$ ) remaining above baseline levels over all.

The purpose of this study was to replicate and extend the pilot study, examining the effectiveness of SRSD instruction on the persuasive essay writing strategies of high school students with ADHD. Previous research has only briefly examined the written expression of students with ADHD. The literature base addressing strategy instruction and students with ADHD is growing but still remains small, with only a handful of studies. Additionally, outside of the pilot for this study, no intervention research has specifically addressed effectiveness of strategy instruction with high school students with ADHD. This study addressed the gaps in all these areas and is important because high 
school students face high stakes assessments, increased expectations of their writing ability, and less time in which to have their writing difficulties addressed. 


\section{$\underline{\text { Chapter } 3}$}

\section{Method}

\section{Experimental Design}

A multiple baseline across participants design, with multiple baseline probes, was used in this study (Kazdin, 1982). Each student was introduced to SRSD instruction in turn, to ensure no student received instruction at the same time. Baseline data measuring each participant's writing performance over time were taken prior to instruction. A functional relationship between the independent variable and the student's progress was established by improvement in the target variables only after the completion of SRSD instruction and if participants still in baseline stayed at pre-intervention levels across baseline.

Setting

The study was conducted during the fall and spring semesters in a high schools in a Midwestern state. The school is made up of over 1700 students. Sixteen percent of the total school population receives special education services, $46 \%$ receive reduced/ free lunch, $28 \%$ are minority students, and $7 \%$ are English language learners. Intervention took place in a location on campus designated by the school, typically an empty office. Sessions were scheduled in either the morning or afternoon, depending on the student's schedule.

\section{Participants}

The following procedure was used to identify five students, four male and one female, four of whom participated in the study. The fifth student was unable to complete the study due to ongoing attendance issues. First, special educators identified students 
believed to have ADHD and difficulty writing. Next, parental consent was obtained (see Appendix A). Then, parents were interviewed by phone to verify that their child had been medically diagnosed with ADHD. Parents were asked to provide the date of their child's identification with ADHD, whether their child was currently on medication, and the type of medication prescribed. A structured interview form was used to ensure all interviews included the same information (See Appendix B). Next, the students' school records were reviewed. Student academic performance, previous testing data, and student IQ were noted, using a standardized file review form. A minimum student IQ of 80 was required for study participation. Additionally, parent and/or teacher responses on the ADHD Rating Scale-IV (DuPaul, Power, Anastopoulos, \& Reid, 1998) were used to verify the presence of eight of the 14 symptoms of ADHD based on the DSM-IV criteria (American Psychiatric Association (APA), 2000). Students were also screened for writing problems using the expressive writing subtest from the Wechsler Individual Achievement Test II (WIAT-II; Psychological Corp., 2001). Students scoring in the below average to low average (i.e., 79-91) were not included in the study.

All the participants were in grades 10 and 11 . None of the participants were currently receiving medication. All participants were fully included in general education for most their academic classes, and received special education services under the Other Health Impaired (OHI) category. None of the students had any other current special education diagnosis and none had passed the writing portion of the school district's Graduation Demonstration Exam at the time of instruction.

Curtis, a Caucasian student, was in $10^{\text {th }}$ grade. While in $6^{\text {th }}$ grade he was diagnosed with ADHD by a physician specializing in behavior issues. Curtis's score on 
the Hyperactivity-Impulsivity (HI) subtest of the ADHD rating scale-IV (ADHD-IV) was $7\left(75^{\text {th }}\right.$ percentile). His score on the Inattention (IA) subscale of the ADHD-IV was 16 $\left(82^{\text {nd }}\right.$ percentile $)$. Hi total score on the ADHD-IV was $23\left(80^{\text {th }}\right.$ percentile). Curtis's Fullscale score on the Wechsler Intelligence Scale for Children (WISC-IV) was 84. He scored in the average range in broad written language (94), and in the low average range in broad reading (89) on the Woodcock-Johnson III Tests of Achievement (WJ-III). His score on the WIAT-II was in the borderline range (77). Finally, Curtis's standard scores on the Clinical Evaluation of Language Fundamentals 3 (CELF-3) scores were: Receptive Language - 78 (borderline range), Expressive Language - 92 (average range), Total Language Score - 84 (low average range). Curtis's IEP called for co-taught classes in which both a general educator and special educator provide content instruction.

The second participant, Noah, was also Caucasian and in the $10^{\text {th }}$ grade. Noah received an ADHD diagnosis in $5^{\text {th }}$ grade after being evaluated by his pediatrician. Noah's score on the HI subscale of the ADHD-IV was 11 , falling at the $86^{\text {th }}$ percentile. His score on the IA subscale was seven $\left(50^{\text {th }}\right.$ percentile $)$. Finally, his total score for the ADHD-IV was 18 , at the $73^{\text {rd }}$ percentile. Noah's Full-scale score on the WISC-III was 87. On the WJ-III, both his broad written language (71) and his broad reading score (71) were in the low range. Additionally, he scored in the deficit range on the written expression subtest of the WIAT-II (63). Finally, on the Metropolitan Achievement Test (MAT) test of language, Noah scored in the $11^{\text {th }}$ percentile for language and in the $2^{\text {nd }}$ percentile for spelling. His most recent IEP stated he received 90 minutes of resource support each day, five days a week. 
Christian, an African American student in the $10^{\text {th }}$ grade, was eligible for free/reduced lunch. His school records stated a psychiatrist provided the ADHD diagnosis but no information was provided as to the date of the diagnosis. Numerous attempts were made to contact the parents for an interview with no response. On the HI subscale of the ADHD-IV, Christian's score was 18 ( $93^{\text {rd }}$ percentile). His score on the IA subscale was $15\left(80^{\text {th }}\right.$ percentile $)$. His total score for the ADHD-IV was 33 , in the $92^{\text {nd }}$ percentile. Christian's Full-scale score on the WISC-IV was 80. On the WJ-III, Christian's scores for both broad written language (80) and broad reading (80) were in the low average range. Additionally, he scored in the borderline range for written expression on the WIAT-II (71). Finally, his Total Language Score on the CELF-IV was in the low average range ( $22^{\text {nd }}$ percentile) and he was in the second percentile on the language test of the MAT. His current IEP stated he received 80 minutes of resource support a day, five days a week.

The final participant, Sarah, was in $11^{\text {th }}$ grade. Her foster mother was unsure of the date of her diagnosis but believed that a psychiatrist had provided the diagnosis. A review of her school records provided documentation dated to 2003, when Sarah was in $6^{\text {th }}$ grade. However, according to her school records, it appears she was receiving services under $\mathrm{OHI}$ prior to that date, although no further information was provided. The only female participant, Sarah was Hispanic, a mother to a 1-year-old son, living in foster care, and eligible for reduced/free lunch. Her score on the HI subscale of the ADHD-IV was 12 (above $97^{\text {th }}$ percentile). Her score on the IA subscale was $10\left(86^{\text {th }}\right.$ percentile) and her total ADHD-IV score was $22\left(93^{\text {rd }}\right.$ percentile). Sarah's Full-scale score on the WISC-III was 83. On the WJ-III her scored for both Broad Written Language (80) and 
Broad Reading (80) were in the low average range. Additionally, her score on the WIAT-II was in the borderline range (72). Her MAT scores were in the $32^{\text {nd }}$ percentile for language, and the ninth percentile for spelling. Her current IEP stated she received 100 minutes of resource support a day, five days a week. 


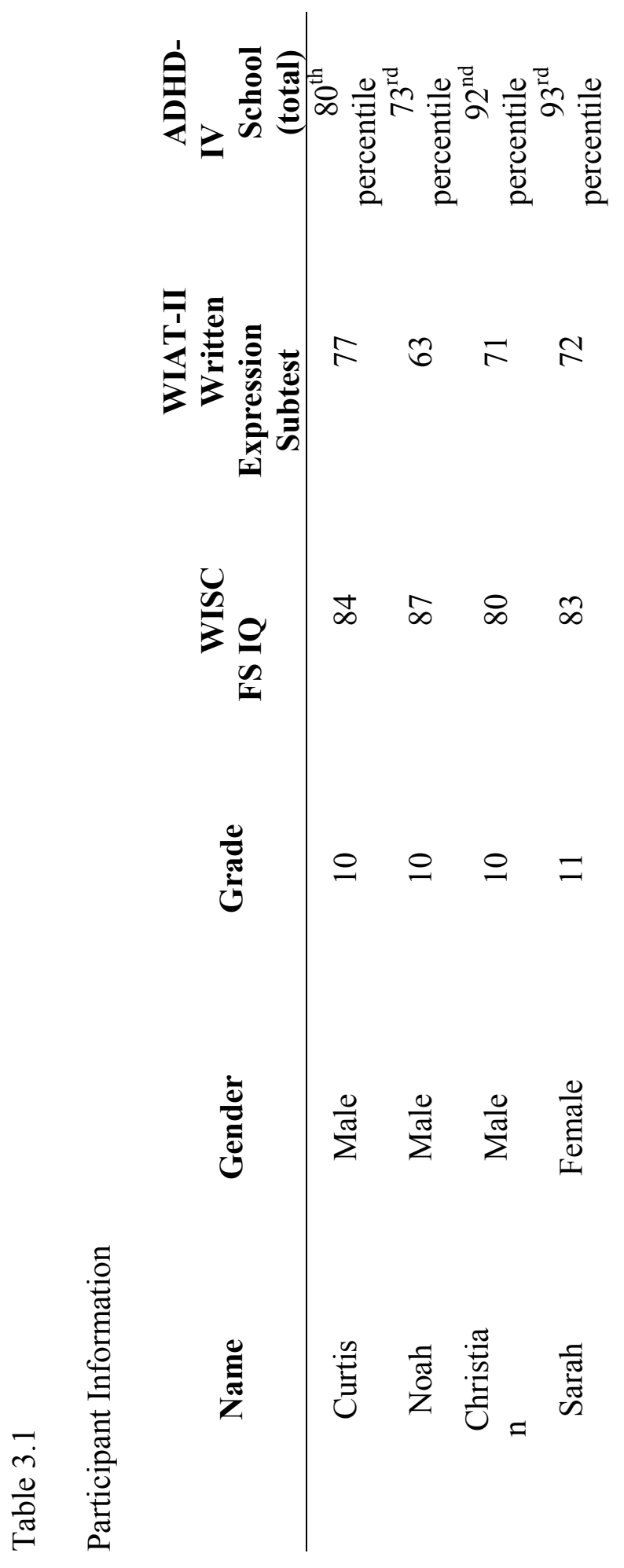




\section{Assessment Measures}

The Wechsler Individual Achievement Test-II (Psychological Corp., 2001) is an individually administered achievement test designed to assist with learning disability diagnosis, special education placement, curriculum planning, and decisions regarding interventions for preschool children through adults. Subtests include: written expression, spelling, listening comprehension, oral language, word reading, pseudoword decoding, reading comprehension, numerical operations, and mathematics reasoning. The Written Expression subtest includes items assessing sentence construction, word fluency, writing fluency, and written responses to visual or verbal cues. Additionally, descriptive and narrative writing tasks are included. The internal consistency reliability estimate of the written expression subtest is above .70 .

The ADHD Rating Scale-IV (DuPaul, et al., 1998) is intended to help identify the frequency of ADHD symptoms of children between the ages of 5 and 18 as reported by a parent or educator. There are two versions of the measure, the ADHD Rating Scale-IV: School Version and the Home version each reflecting the DSM-IV (APA, 2000) criteria. Parents or educators complete a questionnaire made up of a series of 4-point Likert rating scales (0-never or rarely to 3-very often) to describe the frequency of different ADHD characteristics. The 18 questions are divided into those that investigate symptoms of "inattention" and those that measure "hyperactivity-impulsivity." Three raw scores are obtained from each version (e.g., inattention, hyperactivity-impulsivity, total) and converted into percentiles based on the child's gender and age. The reliability of the scale was reported as acceptable for test-retest reliability, internal consistency, and criterionrelated reliability. Additionally, there is strong evidence for discriminative validity. 
Finally, the predictive validity of teacher and parent ratings has been shown to be significant for both the combined and inattention subscales.

Procedures

The four participants were instructed individually in the planning and essay writing strategies by the first author. She received training in the SRSD model and provided SRSD instruction in the pilot for this study (Jacobson \& Reid, in press).

Essay Prompts. Written persuasive essay prompts were used during baseline, intervention, and independent performance phases. The prompts, first used with elementary students (De La Paz \& Graham, 1997), were modified to ensure appropriate language for high school students and were used in the pilot for this study (Jacobson \& Reid, in press; see Appendix C). For example, the words children and toys were changed to students and video games respectively. Additionally, the format of the prompt was changed to reflect the format of the school district's graduation demonstration exam. The order in which prompts were presented was randomized. All students received the same prompts in the same order. After receiving and reading the essay prompt, prompts were read aloud to the participants, to ensure student understanding.

Baseline. During baseline, each participant wrote at least three essays. Students were asked to read the essay prompt to themselves, listen to the prompt read aloud, and write an essay responding to the prompt. Students were instructed to plan their essay, include all the components of an essay, use strong language, and write as much as they could. Students were provided with as much time as they needed to write their essays. Prior to entering the treatment phase a minimum of three contiguous baseline probes was administered. Probes were administered until performance was stable. 
Treatment. Once stable baseline performance was achieved, the first participant received instruction in the planning and essay writing strategies. Instruction continued until the criterion level for independent performance was met (i.e., independently writing an essay with all seven essay parts). The student then moved into the independent performance phase and baseline probes were administered to the next student. These procedures were repeated with each student.

Independent Performance. After completing the treatment phase, each student wrote three essays. Conditions were identical to baseline.

Maintenance. A maintenance probe was administered 2- and 4-weeks after the completion of the independent performance phase for each participant. Conditions were identical to baseline.

Dependent Measures

Time spent planning and writing were recorded for each essay. Each essay was scored for number of essay parts, number of words, number of transition words, and holistic quality. The essays were first transcribed into a word processor and corrected for spelling and punctuation; scorers then worked with the transcribed copies. Percent nonoverlapping data (PND; Scruggs \& Mastropieri, 1998) was computed for number of essay elements, number of words, and holistic quality.

Time Spent Planning. For each essay prompt the instructor monitored the amount of time spent planning prior to writing. The time on the clock was recorded at the beginning and end of planning. After the essay prompt was read aloud, time began. Planning was considered complete once the student began writing on the paper provided for essay writing. 
Time spent writing. The instructor monitored and recorded the amount of time spent writing each essay. The time on the clock was recorded at the beginning and end of writing. Once the student moved from the provided planning sheet to the separate essay paper time began. Time stopped when the student signaled their completion of the task.

Number of essay elements. A complete essay must include all seven possible essay elements. Each element coincides with a part of the essay writing strategy DARE: Develop an introductory paragraph, Add supporting ideas (at least three), Reject at least one argument for the other side and support your opinion, and End with a conclusion. Two raters independently read and scored the number of essay elements included in each essay (see Appendix D). Prior to scoring, raters were trained in procedures and attained reliability greater than 80 percent. Both raters were blind to the study hypotheses and students. Inter-rater reliability for number of essay parts was .90 and was calculated as agreements divided by agreements plus disagreements, multiplied by 100 .

Number of words. The number of words written was calculated by the word count function of the word processor. Reliability was not calculated because this was machine scored.

Transition Words. The number of transition words in each essay was reported. Two readers, directed to count each transitional word or phrase, examined each essay. The readers compared their counts, discussed any differences and determined a total for each essay. The list of transition words and phrases used during instruction was used as a reference.

Quality ratings. Essay holistic quality was rated on a 7-point Likert type scale. A score of seven was the highest quality and a score of one was the lowest quality. Anchor 
essays were obtained through procedures similar to those used in similar studies (Graham \& Harris, 1989; Lienemann \& Reid, 2008; Saddler, Moran, Graham, \& Harris, 2004). Anchor points were based on ratings made by two teachers of general English. First, 18 anchor papers were drawn from essays written by students in general English in response to a persuasive essay prompt. Study participants were not students in the classes. Second, the teachers independently read and rated each essay, placing them into categories of low, medium, or high quality. Together the raters then compared their ratings on each essay, discussing any differences. Finally, the raters then selected one essay as representative of each quality category (low, medium, high) to serve as anchor papers.

Two high school English teachers, blind to the study's hypothesis, rated each paper independently. Prior to scoring the essays the raters received a 45-minute training session. Raters were then presented with anchor papers representing high, medium, and low quality essays, and asked to rate practice essays. They were directed to read each essay attentively but not laboriously to get an overall impression of the writing quality. Anchor papers were then used as a reference to score the essays. Raters were asked to practice until obtaining $80 \%$ reliability. This was achieved in less than 30 minutes of practice. Once reliability was achieved, raters received participants' essays in random order. All information regarding student and phase was removed prior to rating. Using Pearson's correlation coefficient, the interrater reliability for the essays was .90 . General Instructional Procedures

The SRSD model was used to teach a planning and a persuasive writing strategy. The major goals of SRSD are 1) student mastery of the higher-level cognitive processes used in writing; 2) development of self-regulation and independent use of the strategies; 
and 3) the development of positive attitudes about writing (Graham \& Harris, 1993). Instruction was scaffolded, gradually shifting responsibility for the strategy from the instructor to the student. Students were provided with individualized feedback and support throughout the learning process. Additionally, extensive modeling was used to demonstrate both the strategy and the learning processes to the student.

Students moved through the stages of instruction at their own pace, not moving forward until they had met the criteria for doing so. Detailed lesson plans, developed by De La Paz and Graham (1997), were used at each stage of instruction (see Appendix E). The instructor used lesson plan guides and a check sheet to ensure all portions of each lesson were addressed (see Appendix F). Participants received three, 40-minute individual instructional sessions per week until they could independently write an essay with all seven parts. If necessary, lessons were divided over multiple meeting sessions. Instructional Procedures for Teaching the Planning and Essay Writing Strategy

The planning and essay writing strategies used in this study have been used in previous studies (De La Paz, 1999; Jacobson \& Reid, 2008). Developed by De La Paz and Graham (1997), the planning mnemonic STOP is used to help students plan their persuasive essays. STOP stands for "Suspend judgment," "Take a side," "Organize my idea," and "Plan more as you write." These statements help students brainstorm and organize ideas for an effective persuasive essay. The essay writing mnemonic, DARE, has been modified slightly to address essay quality. Instead of prompting students to, "Develop your topic sentence," it will now direct students to "Develop your introductory paragraph," "Add supporting ideas," "Reject possible arguments for the other side," and 
"End with a conclusion." DARE serves as reminder for students to include the ideas developed in planning within an essay containing all the required parts.

Develop Background Knowledge. In the first stage of instruction, the students were introduced to the STOP and DARE strategy mnemonics. First, the STOP mnemonic for planning was introduced. Each step used in the planning process was discussed and its importance explained. After this introduction, the students were asked to repeat the steps and their importance back to the instructor to ensure student understanding. Next, students were asked, "What does the word persuade mean?" During the discussion the instructor and the students defined the word persuade and clarified that it means to support or win approval for a position, belief, or course of action. Once the idea of persuasion was clear to the students, they were asked to explain what makes a good persuasive essay. After discussion, the instructor emphasized that a good persuasive essay: a) makes sense, (b) states and supports a clear position, (c) uses interesting vocabulary, (d) includes all needed essay parts.

The instructor then introduced the persuasive writing mnemonic (DARE) explaining that it is a trick to help remember the components of a persuasive essay. Next, the instructor read a sample essay with the student, and asked the student to identify each essay component as they heard it. As the student identified each component, the instructor wrote the student's response in the appropriate section of the essay component reminder chart. The student was then given a graphic organizer to help him/her remember each of the components of a persuasive essay (see Appendix G). The process was then repeated with another essay. Together, the student and instructor discussed where they thought this type of strategy could be used (e.g., in class essays, trying to convince their 
parents of something). The instructor explicitly mentioned the use of such a strategy in writing essays for required graduation exams and the state writing test. The student was then told that the steps of the strategy must be memorized and that there will be quiz on those steps at the start of next lesson.

Discuss it. In the second stage of instruction the focus remained on the importance and use of the strategies. At the beginning of the session, the student was asked to list the previously introduced mnemonics and define each component from memory.

Memorization of the strategy is important because it allows for its fluent use. If the student has committed the strategy to memory, she or he will be able to use the strategy more efficiently, leaving more room in working memory for the assigned task. At this point, a list of linking/transition words was introduced (see Appendix H). The instructor and the student discussed the use of transition words and where they are used in an essay. They reviewed the list to make sure the student was familiar with, and understood the words. Next, the student was asked again to identify the essay components in the essay read aloud by the instructor. If the student was unable to identify each component in the essay, the process was repeated until they are able to do so. Next, the student read one of their own essays written during baseline and determined how many of the essay parts were included, and how many words were written. During the analysis of the essay, the student and instructor discussed how the essay could be improved. The instructor focused on the need to include transition words, all the essay components and how length can impact clarity. They then discussed the importance of goal setting and how goals can relate to essay writing. The student then graphed the number of essay components included in their essay and the number of words written, so they could continuously 
monitor their progress. At the end of the session, the instructor and student reviewed the number of essay components and number of words included in the student's last essay, and together set a goal for essay length and number of elements for the next essay. The goal was noted on the graph by a dotted line (see Appendix I).

Model it. In the third stage of instruction, the instructor explicitly modeled the use of the strategy, verbally demonstrating the use of self-instructions. Before beginning, the instructor discussed the parts of the STOP and DARE mnemonics. She then developed essay goals of including all the essay parts, and using transition words. The instructor, assisted by the student, then planned for and composed an essay that included all the essay components. As ideas were generated the instructor modeled and talked through the planning process. Ideas were noted on a pre-made planning sheet on which each essay component was listed (see Appendix J). The instructor used self-statements to demonstrate problem definition (e.g., What am I expected to do?); planning (e.g., What do I do next?"); self-evaluation (e.g., "Does that make sense?”); self-reinforcement (e.g., "Exactly!"); and coping (e.g., "I can do this!"). After modeling the strategy, the instructor explained the importance of self-talk. After the essay was written, the student verified that all the essay components were included and graphed the results. The number of words was also counted and graphed. This essay was graphed to provide a model of the entire process that students were expected to go through. Students were reminded that longer essays are often better essays.

Support it. The next stage began with a collaborative writing experience. The instructor and the student first set a goal to include all seven essay elements. Second, they planned the essay together using STOP. The student was expected to take the lead in the 
planning processes with the instructor providing needed support. Third, using the notes generated using STOP, the student wrote a persuasive essay, using the DARE mnemonic as a guide. Fourth, the student determined if each essay element had been included in the essay. Each was noted by highlighting it in the text. After the results were graphed, the student determined if their goal had been reached. Fifth, the instructor and the student discussed the strategy and how it helped improve the student's essay quality.

Independent Performance. When the student successfully wrote an essay with all seven essay components without assistance, he or she moved into the independent performance stage. Students were presented with an essay prompt and asked to write an essay independently. All supports were discontinued.

Fidelity of Treatment. To ensure strategy instruction was presented consistently the following procedures were in place. First, the instructor followed a checklist listing each step of the lesson. Next, an outside observer, following with the same checklist as used by the instructor, observed $20 \%$ of all lessons. The point-by-point method (Kazdin, 1982) was used to calculate interobserver agreement. Treatment fidelity was $99 \%$. 


\section{Chapter 4}

Results

Figure 4.1 shows the number of essay parts included in each student's persuasive essays. Figure 4.2 shows the length (i.e., number of words) in each essay. Figure 4.3 shows the holistic quality ratings of each essay. Table 4.1 shows the planning and writing time of each student for each probe. No maintenance data was gathered for Sarah, as the school year came to an end.

Planning Time

At baseline, students spent zero minutes planning before writing. Each student immediately began writing once the prompt had been read. After instruction noticeable increases in planning time were seen in all students. Planning time means for Curtis, Noah, Christian, and Sarah across independent performance were, 21minutes, 36.3 minutes, 13.3 minutes, and 6.3 minutes, respectively. At the 2- and 4-week maintenance points students continued to spend more time planning than in baseline, though not at the same levels as independent performance. At the 2-week point, Curtis, Noah, and Christian, spent 13 minutes, 21 minutes, and 2 minutes planning, respectively. Fourweeks after instruction Curtis, Noah, and Christian spent 15 minutes, 14 minutes, and 3 minutes planning, respectively. No maintenance data was collected for Sarah due to the end of the school year. PND for all students was $100 \%$ in all phases of the study. Writing Time

Prior to instruction students wrote their essays quickly, beginning as soon as the prompt had been read. At baseline, the average amount of time spent writing was under 10 minutes. Curtis, Noah, Christian and Sarah spent an average of 4.6 minutes, 5.5 
minutes, 6 minutes, and 3.5 minutes respectively. After instruction, writing time increased dramatically. Mean writing time, respectively, was 45, 33, 24.7, and 18.6 minutes for Curtis, Noah, Christian, and Sarah. Percentage increases in writing time for Curtis, Noah, Christian, and Sarah were $877 \%, 500 \%, 311.7 \%$, and $431.4 \%$ respectively. Increases in writing time remained at maintenance, although at slightly lower levels. Curtis, Noah, and Christian spent 29 minutes, 31 minutes, and 20 minutes writing, on average, at maintenance. PND for all students was $100 \%$ in all phases of the study. Number of Essay Elements

Prior to instruction all participants demonstrated stable baselines, with no participants including more than three elements in baseline essays. The mean number of essay elements included by each student at baseline was $1.3,1.5,1$, and 0.5 elements for Curtis, Noah, Christian, and Sarah respectively. During instruction all participants independently wrote two essays containing all seven required essay elements. At independent performance, participants were inconsistent in their ability to include all the necessary essay elements. The means for Curtis, Noah, Christian, and Sarah, respectively, were 6.3, 6.7, 6 and 6 required essay elements. No student included all the essay elements in all three essays in the independent performance phase. Furthermore, neither Christian nor Sarah included all the required elements in any essay in this phase. However, students' percentage increase in the total number essay elements included was $386.9 \%, 346.7 \%, 500 \%$, and $1100 \%$ for Curtis, Noah, Christian, and Sarah, respectively. At the 2- and 4-week maintenance points each student wrote at least one essay with all the required elements. The means for the maintenance phase were 6.5 elements, 6.5 elements and 7 elements for Curtis, Noah, and Christian, respectively. 
Number of Words

At baseline, the mean number of words for Curtis, Noah, Christian, and Sarah was $41,40,73.4$, and 58.9, respectively. The mean number of words included at independent performance for Curtis, Noah, Christian, and Sarah was 206, 206.3, 291.3, and 197.7, respectively. These means represent percentage increases of, 402.4\%, 415.8\%, 296.9\% and $235.7 \%$ over baseline for Curtis, Noah, Christian, and Sarah, respectively. At the 2and 4-week follow ups, effects were maintained by Curtis, Noah, and Christian, although slightly below the levels at independent performance. The mean number of words at maintenance was 189, 160, and 237 for Curtis, Noah, and Christian, respectively. For all phases, PND was $100 \%$.

Transition Words

Prior to instruction only one student used any transition words in an essay. Christian used two transition words in one essay, a mean of 0.4 across baseline. During independent performance the mean number of transition words for Curtis, Noah, Christian, and Sarah was 9, 4, 6, and 5.3, respectively. At the 2-week follow-up the effects were maintained by Curtis and Noah, with Christian's performance still well above baseline. Curtis, Noah, and Christian included 9, 4, and 5 transitions words respectively at the 2-week follow-up. At the 4-week follow up Curtis included 14 transition words, more than in any other essay. Noah's performance remained consistently above baseline, including four transition words. Christian included five transition words in his final essay. All students' PND was $100 \%$ for all phases of the study. 
Quality Ratings

Following instruction, all students' quality ratings improved dramatically over baseline performance. Baseline performance was the same for Curtis, Noah, Christian, and Sarah; each student's essays received a quality rating of one, the lowest score available. In independent performance the mean quality ratings for Curtis, Noah, Christian, and Sarah were 4, 3.17, 4.5, and 3, respectively. Mean percentage increases, respectively, were $200 \%, 217 \%, 350 \%$, and 200\% for Curtis, Noah, Christian, and Sarah. At the 2-week follow-up all students' performance had decreased somewhat from independent performance but remained considerably above baseline levels, 2.5, 2.5, and 3.5 for Curtis, Noah, and Christian, respectively. At the 4-week follow-up Noah's quality ratings remained stable (2.5). However, both Curtis and Christian's 4-week performance increased to 4.5, the highest performance for Curtis and even with Christian's level in independent performance. 
Figure 4.1

Effects of SRSD Instruction on Essay Elements

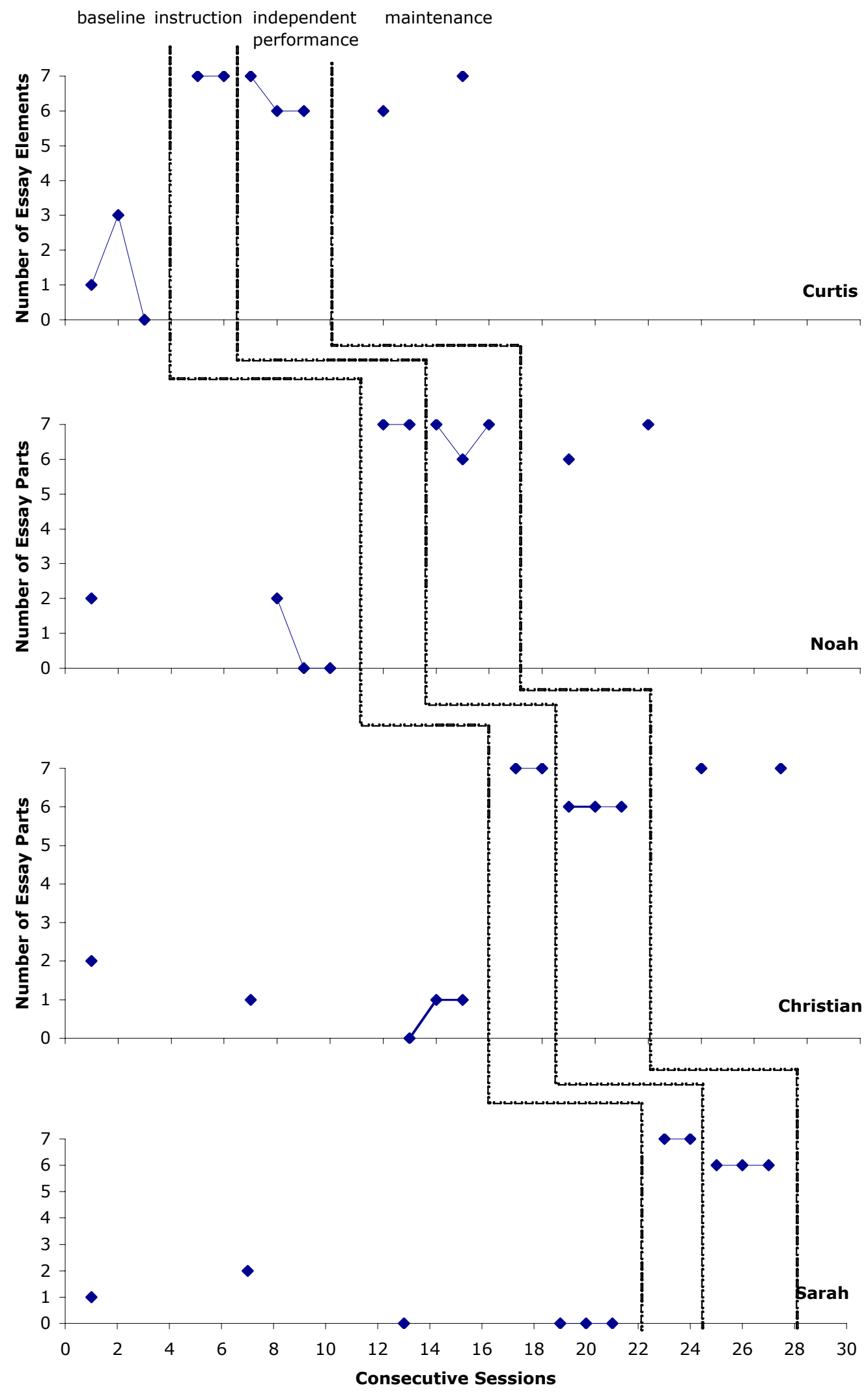


Figure 4.2

Effects of SRSD Instruction on Number of Words

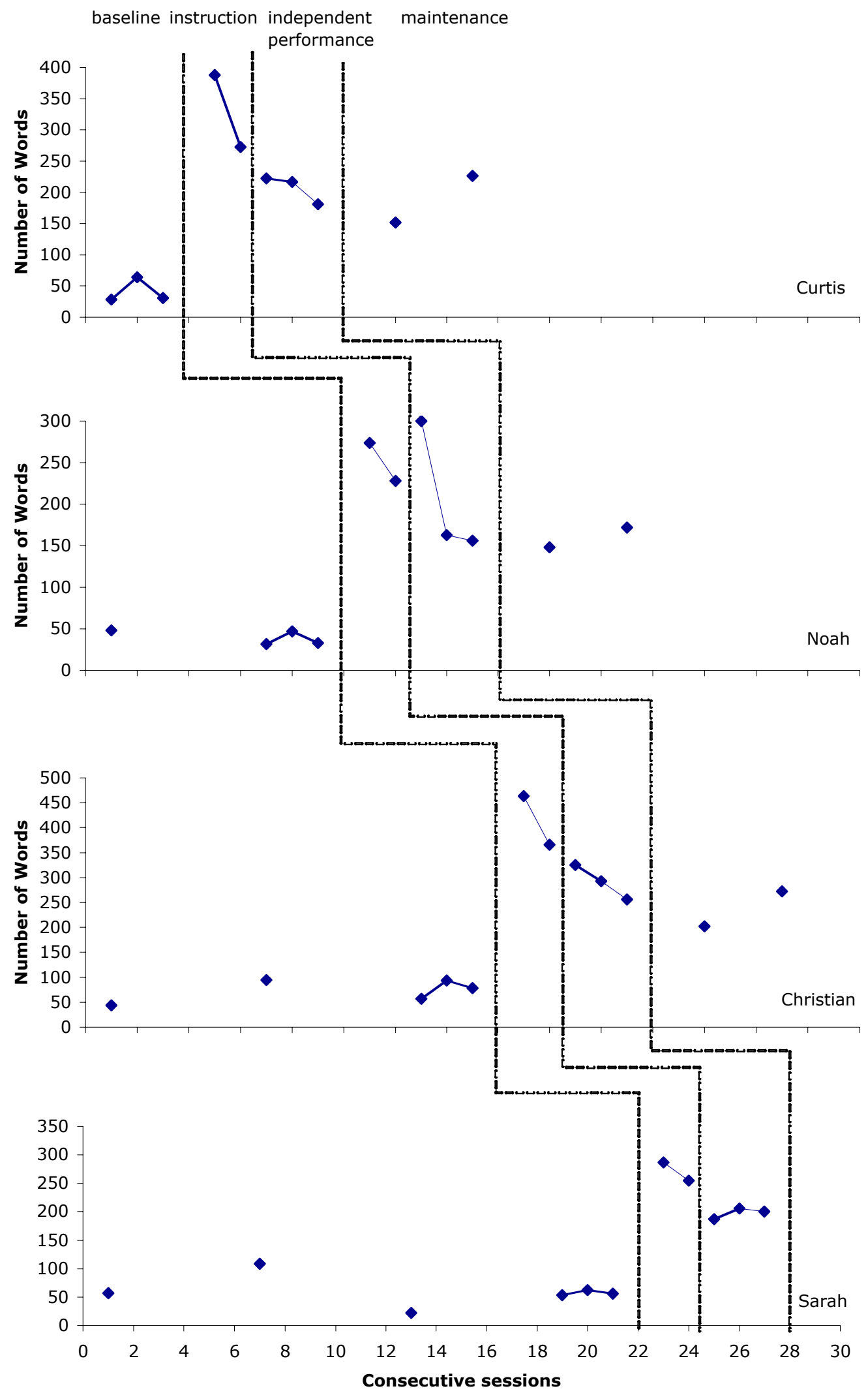


Figure 4.3

Effects of SRSD Instruction on Holistic Quality

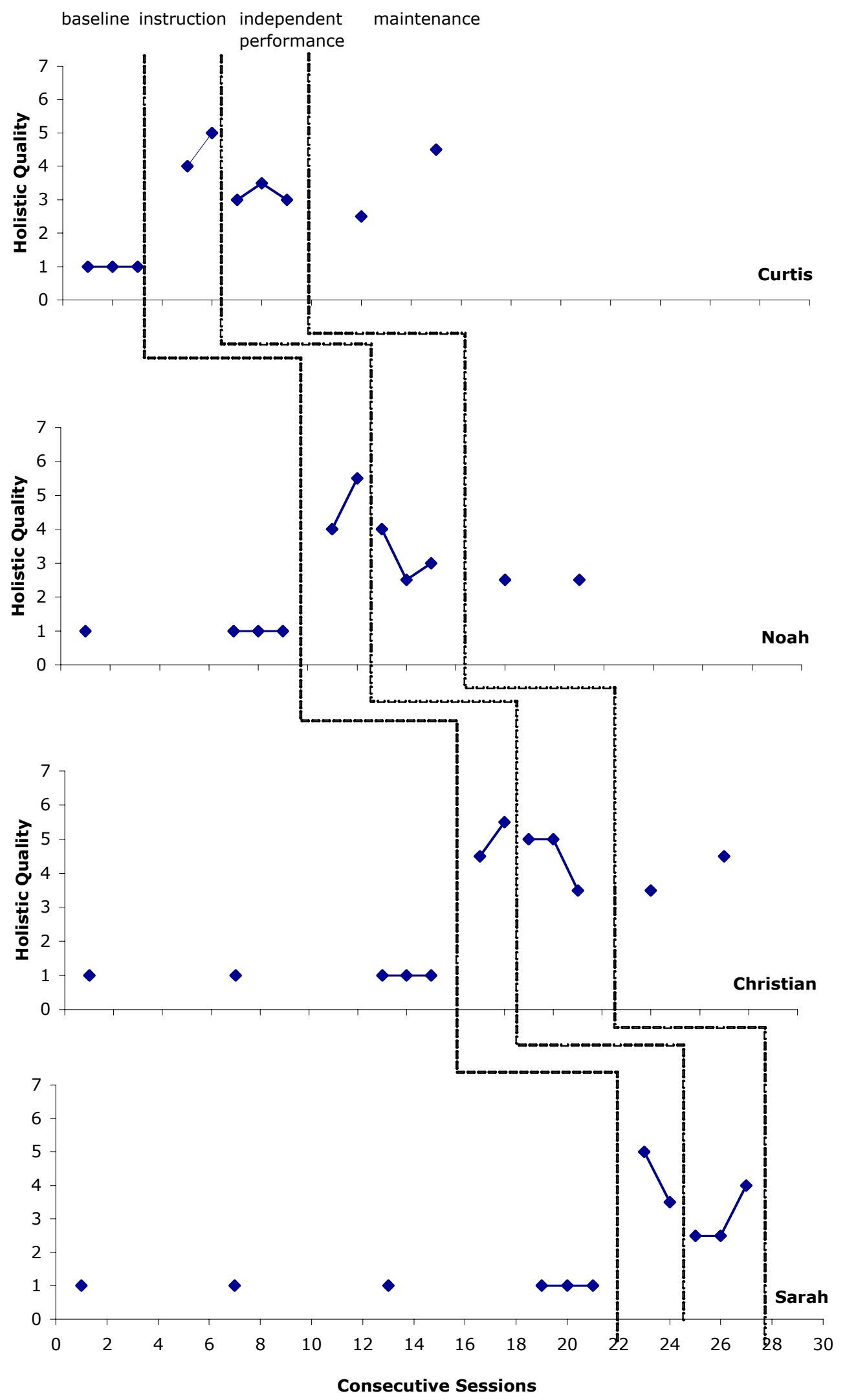




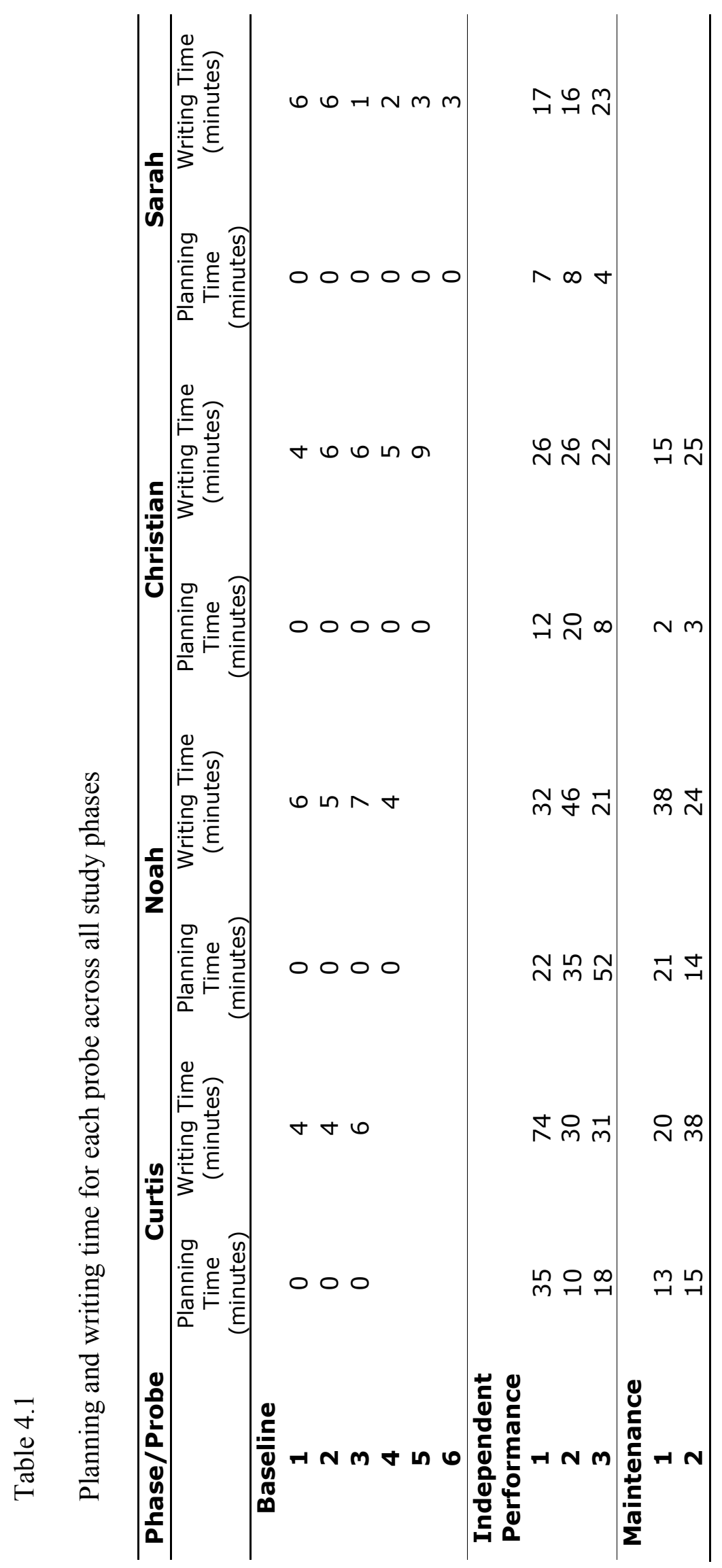




\section{$\underline{\text { Chapter } 5}$}

Discussion

\section{Effects of Dependent Measures}

At baseline, students' essays were generally short, largely incomplete, and of poor holistic quality. Students failed to plan, spent little time writing, and generally included no transitional words or phrases in their writing. After instruction, all students wrote longer, more complete, and higher quality essays. Students overtly planned, increased the time they spent writing and increased the number of transitional words and phrases included in each essay. PND for all dependent measures was 100\% across all phases of the study for all students, suggesting a highly effective intervention.

As in the pilot study (Jacobson \& Reid, in press), planning time was directly measured. Planning time is important to examine because research has shown that increases in planning time contribute to improvements in writing quality (Hayes \& Nash, 1996). After completing instruction, all participants demonstrated an increase in the amount of time spent planning from baseline to follow-up phases. Although paper was provided and directions suggested planning, students made no notes prior to beginning their baseline essays. Rather, each student began writing directly after the prompt was read. After instruction, all students substantially increased their planning time and maintained their performance levels above baseline at the 2- and 4- week follow-up probe. All three students from whom follow-up data were taken saw decreases in planning time from the independent performance phase to follow-up.

The decrease in planning time was most evident in Christian. Interestingly, though there were substantial decreases in planning time, the essays written in the follow- 
up phase were of similar length to and more complete than (all seven essay elements) those written at independent performance. Additionally, his decreases did not necessarily correspond to substantial decreases in writing time. At the 2-week follow-up Christian's writing time was below that seen in independent performance. However, at the 4-week probe writing time was similar to that seen in independent performance, despite planning times for both probes of less than five minutes. In spite of his decrease in planning time during the follow-up phase, Christian's holistic quality ratings remained at or above the median (i.e., 3.5 to 4.5 ), with the highest mean quality scores overall. Based on the fact that Christian did continue to make a written plan and reference it both while he wrote and after he completed his essay, it appears that he became more efficient in his planning once he understood planning as a strategy. While we can nott be sure, it seems that after mastering the planning strategy, he was able to plan, putting less information down, but still having a better idea of what he wanted to write.

In addition to time spent planning, time spent writing was also measured. Previous studies with students with ADHD have not directly examined changes in time spent writing but positive effects have been seen in studies of other populations (e.g., Graham et al., 2005; Harris, Graham \& Mason, 2006). In the current study, considerable increases in the amount of time spent writing were seen across all students. At baseline, no student spent more than nine minutes writing an essay. After instruction, all students' mean writing times were above 18 minutes. Research suggests that these increases in planning and writing time influence the quality of students' writing (e.g., Jacobson \& Reid, in press; Saddler, 2006; Sexton, Harris, \& Graham, 1998; Troia \& Graham, 2002).

That no student included all the required essay elements in all essays during the 
independent performance phase is a concern. The need to include all the essay elements was major a focus of the provided instruction. Students self-monitored this component by graphing and the planning sheets prompted students to include all the required elements. Further, in order to write a persuasive essay that is complete and of high quality it must have all the necessary parts. Given that participants did independently include all the essay elements during instruction, it was expected they would continue to do so during independent performance. It is not clear why they failed to include all the required essay elements. For the majority of the essays (eight of 11) the missing component was "reject the other side," which was also the element most often excluded from persuasive essays written by both children and adults (Nippold, Ward-Lonergan, \& Faning, 2005). While the students usually made mention of the other side's perspective, they generally failed to provide the explanation necessary to reject that side's argument. To explain and reject the opposite side of an argument, the students must change their thinking midway through their essay, and examine the idea from another perspective. Research suggests that individuals with ADHD have difficulty quickly and accurately shifting their attention from one task to another (Barkley, 1997; Gualtieri \& Johnson, 2006). The need to examine an argument from another perspective could represent a separate task, and thereby increase the difficulty for a student with ADHD. Given this idea, students with ADHD are likely to benefit from more explicit instruction addressing the "reject the other side" component of DARE. By clarifying how to reject the other side effectively, and providing increased practice in planning and writing this portion of their essay, students may fully master the strategy and write more effective essays. Further, given the number of years they have struggled with writing, additional instructional time may also be 
necessary for high school students to master the strategy completely.

After instruction, students dramatically increased the number of words per essay over baseline performance. These increases are pronounced and students' overall performance remained well above baseline levels at both the 2- and 4-week follow-up points. The improvements on this dependent measure suggest a strong treatment effect. While the overall performance was strong it is important to note the decelerating trend seen in Christian's performance through instruction and across the independent performance phase. Christian included fewer words in each subsequent essay during these phases. While it is unclear as to why his performance was not stable, there are a few important items to note: first, over this time period Christian's overall academic performance declined, with teachers reporting increases in incomplete assignments and poor preparation for in-class assessments. Second, there was a spike in the number of times Christian was sent to the office for problem behavior during this time period. Finally, this decline was not seen across other dependent measures, and did not appear to influence the overall quality of his essays.

In this study there was an increased focus on the use of transition words, with more explicit instruction and discussion of their purpose and use than provided in the pilot study. Accordingly, students made large increases in the number of transition words they included in their work. At baseline only one student, Christian, used any transition words (i.e., two) in a single baseline essay. After instruction each student increased to at least four transition words per essay and maintained their performance at the 2- and 4week follow-ups. In the independent performance phase, the average number of transition words used was 6.2. Both quality raters made note of the increased use and effectiveness 
of the transition words chosen by the students. The average percentage increase of holistic quality in this study was $132 \%$ greater than in the pilot study. Perhaps the increases in transition words may have played a part in the improvements in the holistic quality ratings in this study.

The improvements in holistic quality are possibly the most important results of this study. Holistic quality can be considered a measure of the overall effectiveness of a piece of writing. As suggested by the raters, experienced English teachers and scorers of state assessment tests, holistic quality is the basis for the evaluation of most writing, whether in a classroom or on a high stakes test. After instruction, quality ratings increased substantially over baseline performance. The results were striking and were similar to improvements in student performance seen in previous studies (Jacobson \& Reid, in press; Lienemann \& Reid, 2008; Reid \& Lienemann, 2006a;). It is promising that such improvement can be seen after such a small instructional period. Students whose writing received the lowest possible holistic quality scores at baseline were able to increase their performance to what is considered average in five lessons, and were able to maintain those performance levels two and four weeks after instruction. The continued level of improvement by students at the 2- and 4- week follow-up is also encouraging, given that strategy maintenance is a concern for students with ADHD (Kofman et al., 2008).

SRSD and Students with ADHD

The SRSD model provides explicit self-regulation instruction while highlighting the importance of learning to use a strategy effectively to accomplish a task. This explicit instruction is important because current theories of ADHD emphasize that deficits in self- 
regulation are the basis for ADHD (Barkley, 1997). In the current study, students received simultaneous self-regulation instruction and academic strategy instruction. This is particularly appropriate for students with ADHD because instruction in self-regulation strategies has been shown to be effective in improving maintenance of effort and focus (Reid et al., 2005) — areas with direct ties to academic performance.

Self-monitoring, a component of self-regulation, is a common area of difficulty for students with ADHD. The poor academic performance of individuals with ADHD may be caused, in part, by poor self-monitoring skills (Barkley, 1997). In this study, students self-monitored their performance by graphing the number of words and essay elements they included in their essays. After the introduction of the self-monitoring component, students immediately increased the number of words and required essay elements included in their essays. These effects mirror those seen in previous studies with students with ADHD (De La Paz, 2001; Jacobson \& Reid, in press; Lienemann \& Reid, 2008; Lienemann et al., 2006; Reid \& Lienemann, 2006a).

The self-monitoring component appeared to have the greatest influence on Christian. Prior to beginning each of the 2- and 4-week follow-up essays, he first asked how many words and essay parts he had included in his most recent essay. He also asked, "How good was it?" After being told he had not included all the essay elements in his previous essay he made sure he included all the elements in the final two essays, taking time to reread his work when he finished and check it against his written plan.

Research also suggests that students with ADHD often struggle with strategic planning and goal setting (Barkley, 1997; Kliegel, Ropeter, \& Mackinlay, 2006). Instruction following the SRSD model also addresses difficulties in goal setting, holding 
goals in mind, and directing behavior to achieve set goals. By discussing the importance of goals and clearly monitoring progress throughout instruction, students discover the meaning and purpose of a goal, measure their progress toward it, and begin learning to keep that goal in mind. After instruction in goal setting, combined with self-monitoring, planning, and essay writing, students set goals of including all the essay elements and writing more words and were, for the most part, able to achieve those goals. Students spent more time planning and writing, wrote more words, included more essay elements, and used greater numbers of transition words within their essays. Perhaps most importantly, dramatic increases were seen in holistic quality, a measure frequently used in classrooms and on high stakes assessments at the high school level.

Unlike previous research that has shown that individuals with ADHD often have difficulty maintaining the used of a strategy (Kofman et al., 2008), students in this study continued to use the planning and writing strategies through the remaining phases of the study. Curtis, Noah, Christian, and Sarah were not only able to use the strategies consistently, but to use them correctly. During the independent performance and maintenance phases, each student independently created planning sheets for each essay identical to those provided during instruction. Students followed each step, listing arguments for both sides, clearly marking the side they chose, and identifying and organizing their ideas before writing. It is important to note that the presence the instructor, who also administered the writing prompts, may have acted as a prompt to create the planning sheets.

One of the benefits of strategy instruction is that it allows for personalization of the strategy once the steps have been learned to automaticity (Reid \& Lienemann, 2006b). 
Sarah made some changes, not to the strategy itself, but to how she performed it by adding an additional element to help her organize the information while she planned. First, she chose a color with which to create the planning sheet itself. Then she used another color for her notes for either side. Finally, she used a third color to identify and organize her ideas (i.e., marking chosen ideas with a star and then numbering them in order of use). She repeated this process for each essay in independent performance. This adaptation of the strategy is particularly interesting because research suggests that color may have a positive influence on the sustained attention of individuals with ADHD (Zentall, 1986). Additionally, color may help students to read more carefully and may be beneficial to tasks requiring extended responding (Belfiore, Grskovic, Murphy, \& Zentall, 1996). Future research may choose to examine the influence of color on the effectiveness of strategy instruction for students with ADHD.

Finally, it is important to note that none of the students in the study were currently taking medication for ADHD and its symptoms. In much of the previous research addressing this population, students were currently on medication to help manage their symptoms (De La Paz, 2001; Lienemann \& Reid, 2008; Reid \& Lienemann, 2006a). While there is strong evidence to suggest that stimulant medication may improve academic accuracy (Evans, Pelham, Smith, Bukstein, Gnagy, \& Greineret, et al., 2001), it is not clear that these results translate to long-term improvements in academic performance. The results of this study, combined with those seen in the pilot study (Jacobson \& Reid, in press), suggest that strategy instruction following the SRSD model is effective for students who are not medicated. These results are important for a number of reasons. First, medication taken for ADHD symptoms is frequently discontinued after 
a year or two (Bussing, Zima, Mason, Hou, Garvan, \& Forness, 2005). Second, adolescent students are less likely than younger students to take medication for ADHD (Castle, Aubert, Verbrugge, Khalid, \& Epstein, 2007) and third, for a significant minority of individuals with ADHD medication is not effective.

Limitations and Suggestions for Future Research

There are several limitations to this study. First, maintenance probes were only taken 2- and 4- weeks after instruction, making it impossible to determine whether or not long-term effects were maintained. Long-term strategy maintenance is a concern for students with ADHD. It would be beneficial to have more data points over a longer period of time to better verify students' maintenance of the strategies. Second, instruction was provided in a one-to-one setting. Future research will be necessary to determine the effectiveness of SRSD instruction in small group or whole class environments. This information will be important because most high school students with ADHD receive the majority of their instruction in general education classrooms (Trout et al., 2007). Third, persuasive essay writing was the only genre addressed in this study. While such essays are a frequent high school writing requirement, future research should examine the effectiveness of such instruction on other types of expository and narrative writing of high school students with ADHD. Fourth, generalization is a concern. At present, there have been no studies of adolescent students with ADHD addressing the generalization of SRSD instruction to other writing genres. Research also has not addressed the generalization of such instruction from one setting to another (e.g., students' ability to apply strategies learned in one-to-one setting to a classroom or high stakes assessment). For instruction to truly influence performance, students must 
effectively use the strategies they have learned in the situations that demand them. Fifth, instruction focused only on planning and writing. Instruction in revising and editing was not included. The persistence and attention to detail required by these other components of the writing process are likely to be difficult for this population (Zentall, 2005). Future research is needed to address the effectiveness of SRSD instruction in improving these components of the writing process with students with ADHD. Sixth, the clear improvement in holistic quality notwithstanding, there is obvious room for improvement. Overall, after instruction, the average holistic quality was nearly at the median (3.42 at independent performance; 3.5 at maintenance). After instruction, Sarah's and Noah's average quality scores were low-3, and 3.17, respectively. Future research examining holistic quality and instruction in mechanics and revision would be beneficial. Seventh, though a certified teacher trained in SRSD provided instruction, she was not a certified English teacher. Perhaps SRSD instruction would be even more effective for this population if provided by an instructor more familiar with the teaching and assessing of writing at the high school level. Future research addressing instruction by English teachers, trained in SRSD, would be beneficial. Finally, although the results of this study are consistent with previous studies examining the effectiveness of SRSD instruction with students with ADHD (De La Paz, 2001; Jacobson \& Reid, in press; Lienemann \& Reid, 2008; Reid \& Lienemann, 2006a), it is one of only two studies addressing high school students with ADHD. Moreover, both studies addressing this population included participants from the same midwestern high school. It would be useful for future research to replicate the studies in a different type of community (e.g., rural, urban) to 
establish the effectiveness of SRSD instruction with students with ADHD in different environments.

Implications

The current study does more than replicate the findings of Jacobson and Reid (in press). It extends it in the following ways, first, it provides evidence that strategy instruction using the SRSD model can be effective in improving the writing of a variety of students with ADHD. In the pilot study all the participants were Caucasian, males, from similar socio-economic backgrounds. This study included a wider variety of students including Caucasian, African-American, and Hispanic students and those receiving reduced/free lunch, all who achieved similar improvements after instruction. Additionally, the students in this study exhibited differing ADHD symptoms, and intensities, according to the results of the ADHD-IV rating scales completed by their English teachers. This information was not available in the pilot study. Although the students' results varied widely on each of the subscales, showing different levels of hyperactive/impulsive or inattentive behavior, each student demonstrated similar improvements in their persuasive essay writing. Additionally, the study included a female participant, the only female high school student with ADHD included in the SRSD research thus far. The inclusion of female participants is important because, of school age students identified as having ADHD, the male-to-female ratios vary from 9:1 to $3: 1$ depending on how the sample is identified (Gaub \& Carlson, 1997). Because of the significantly smaller number of females identified with ADHD, the body of research focusing on this population is extremely limited. Research suggests that adolescent girls with ADHD have more psychological distress than males (Rucklidge \& Tannock, 2001). 
Lee and Hinshaw (2006) found that these internalizing symptoms were significantly correlated with a number of factors, including academic achievement. Identifying instructional strategies that are effective for these students is important. The inclusion of additional female students should be a priority in future research.

Second, the results suggest that increased explicit instruction in the use of transitional words and phrases as a part of SRSD instruction may positively influence the holistic quality of the persuasive essays written by students with ADHD. With the increase in time and direct instruction provided for instruction addressing transitions, students increased the holistic quality of their essays when compared to the results of the pilot study. Other factors (e.g., student interest, essay topic etc.) may also have influenced these results.

Further, the study provides additional evidence that a rather brief intervention (five to eight sessions), using readily available techniques (SRSD instruction) that are well validated, functional, and accepted by classroom teachers (e.g., Graham, Harris, \& Reid, 1992; Reid, 1996), can have an obvious effect on the writing performance of high school students with ADHD. Students were provided with instruction for a relatively short amount of time, improved across all dependent measures, and were able to maintain those effects after instruction. This may be especially important when working with high school students because the time allotted for a specific unit of instruction in a high school classroom is fairly short. Students and teachers alike may benefit from the speed and effectiveness of such instruction. The fairly small time span required may be particularly useful for special educators working in a resource room setting. Such instruction could be provided in a resource setting as additional support for the writing 
instruction being provided in the general education classroom. It can also be easily adapted to meet the heterogeneous learning needs of students who receive small group instruction in a pull-out or resource room setting.

In conclusion, this study adds to the small but growing literature base addressing the use of the SRSD model to improve the expository writing of students with ADHD (De La Paz, 2001; Jacobson \& Reid, in press; Lienemann \& Reid, 2008). The results suggest that SRSD instruction can be effective in improving the persuasive essay writing of high school students with ADHD. Additionally, the results support the idea that students with ADHD benefit from instruction that directly addresses working memory and executive functioning deficits. The next steps should include examining the effectiveness of classroom-wide SRSD instruction on the writing of students with ADHD. Furthermore, it will be important to examine the model's effectiveness on the target population when an experienced English teacher provides instruction. 


\section{References}

Achieve. (2006). Closing the expectations gap 2006: Annual 50-state progress report on alignment of high school policies with the demands of college and work. Washington, DC: Author.

American Psychiatric Association (2000). Diagnostic and statistical manual of mental disorders $\left(4^{\text {th }}\right.$ ed.). Washington, DC: Author.

Applebee, A. N., \& Langer, J. A. (2006). The state of writing instruction in America's schools: What existing data tell us. Albany: Center for English Learning \& Achievement, University at Albany, State University of New York.

Barkley, R. A. (1997). Behavioral inhibition, sustained attention, and executive functions: Constructing a unifying theory of ADHD. Psychological Bulletin, 121, 65-94.

Barkley, R. A. (1998). Attention deficit hyperactivity disorder, $2^{\text {nd }}$ ed.: A handbook for diagnosis and treatment. New York: Guilford.

Barkley, R. A. (2006). Attention-deficit hyperactivity disorder, $3^{\text {rd }}$ ed.: A handbook for diagnosis and treatment. New York: Guilford Press.

Belfiore, P. J., Grskovic, J. A., Murphy, A. M., \& Zentall, S. S. (1996). The effects of antecedent color on reading for students with learning disabilities and cooccurring attention-deficit/ hyperactivity disorder. Journal of Learning Disabilities, 29, 432-438.

Benezra, E. \& Douglas, V. I. (1988). Short-term serial recall in ADDH, normal, and reading-disabled boys. Journal of Abnormal Child Psychology, 16, 511-525.

Berk, L. E. (2003). Child development. Boston, MA: Allyn and Bacon. 
Bussing, R., Zima, B., Mason, D., Hou, W., Garvan, C., \& Forness, S. (2005). Use and persistence of pharmacotherapy for elementary school students with attention deficit/hyperactivity disorder. Journal of Child and Adolescent Psychopharmacology, 15, 75-87.

Campbell, S. (2000). Attention-deficit/hyperactivity disorder: A developmental view. In A. J. Sameroff, M. Lewis, \& S. M. Miller (Eds.), Handbook of developmental psychopathology (2nd ed.; pp. 383-401). New York: Kluwer Academic/Plenum Publishers.

Carlson, C. L., \& Tamm, L. (2000). Responsiveness of children with attention deficithyperactivity disorder to reward and response cost: Differential impact on performance and motivation. Journal of Consulting and Clinical Psychology, 68, 72-83.

Castle, L., Aubert, R. E., Verbrugge, R. R., Khalid, M., \& Epstein, R. S. (2007). Trends in medication treatment for ADHD. Journal of Attention Disorders, 10, 335-342. Center on Education Policy. (2007). State high school exit exams: Working to raise test scores. Washington, DC: Author.

Center of Education Policy. (2008). State high school exit exams: Students with disabilities. Washington, DC: Author.

Clark, C., Prior, M., \& Kinsella, G. (2002). The relationship between executive function abilities, adaptive behaviour, and academic achievement in children with externalizing behaviour problems. Journal of Child Psychology and Psychiatry, $43,785-796$. 
Cornoldi, C., Barbieri, A., Gaiani, C., \& Zocchi, S. (1999). Strategic memory deficits in attention deficit disorder with hyperactivity participants: The role of executive processes. Developmental Neuropsychology, 15, I53-71.

De La Paz, S. (1997). Strategy instruction in planning: Teaching students with learning and writing disabilities to compose persuasive and expository essays. Learning Disability Quarterly, 20, 227-248.

De La Paz, S. (1999). Self-regulated strategy instruction in regular education settings: Improving outcomes for students with and without learning disabilities. Learning Disabilities Research and Practice, 14, 92-106.

De La Paz, S. (2001). Teaching writing to students with attention deficit disorders and specific language impairment. The Journal of Educational Research, 95, 37-47.

De La Paz, S. (2005). Effects of historical reasoning instruction and writing strategy mastery in culturally and academically diverse middle school classrooms. Journal of Educational Psychology, 97, 139-156.

De La Paz, S. (2007). Managing cognitive demands for writing: Comparing the effects of instructional components in strategy instruction. Reading \& Writing Quarterly: Overcoming Learning Difficulties, 23, 249-266.

De La Paz, S., \& Graham, S. (1997). Strategy instruction in planning: Effects on the writing performance and behavior of students with learning difficulties. Exceptional Children, 63, 167-181. 
De La Paz, S., Swanson, P. N., \& Graham, S. (1998). The contribution of executive control to the revising by students with writing and learning difficulties. Journal of Educational Psychology, 90, 448-460.

DuPaul, G.J., Power,T.J., Anastopoulos, A.D., \& Reid, R. (1998). ADHD Rating ScaleIV: Checklists, norms and interpretation. New York: Guilford.

Englert, C. S., \& Mariage, T. V. (1991). Shared understandings: Structuring the writing experience through dialogue. Journal of Learning Disabilities, 24, 330-342.

Evans, S. W., Pelham, W. E, Smith, B. H., Bukstein, O., Gnagy, E. M., \& Greiner, A. R. et al, (2001). Dose-response effects of methylphenidate on ecologically valid measures of academic performance and classroom behavior in adolescents with ADHD. Experimental and Clinical Psychopharmacology, 9, 163-175.

Fergusson, D. M., Horwood, L. J., \& Lynskey, M. T. (1993). Prevalence and comorbidity of DSM-III-R diagnoses in a birth cohort of 15 year olds. Journal of the American Academy of Child \& Adolescent Psychiatry. 32,1127-1134.

Forness, S., \& Kavale, K. (2002). Impact of ADHD on school systems. In P. Jensen \& J. Cooper (Eds.), Attention deficit hyperactivity disorder: State of the science, best practices (pp. 24-1-24-20). Kingston, NJ: Civic Research Institute.

Frankenberger, W., \& Cannon, C. (1999). Effects of Ritalin on academic achievement from first to fifth grade. International Journal of Disability, Development and Education, 46, 199-221. 
Frazier, T. W., Youngstrom, E. A., Glutting, J. J., \& Watkins, M. W. (2007). ADHD and achievement: Meta-analysis of the child, adolescent, and adult literatures and a concomitant study with college students. Journal of Learning Disabilities, 40, 4965.

Gaub, M., \& Carlson, C. L. (1997). Gender differences in ADHD: A meta-analytic and critical review. Journal of the American Academy of Child \& Adolescent Psychiatry, 36, 1036-1045.

Graham, S. (2006). Writing. In P. Alexander \& P. Winne (Eds.), Handbook of educational psychology (pp. 457-477). Mawah, NJ: Erlbaum.

Graham, S. (1990). The role of production factors in learning disabled students compositions. Journal of Educational Psychology, 82, 781-791.

Graham, S. \& Harris, K. R. (2005). Writing better: Teaching writing process and selfregulation to students with learning problems. Baltimore, MD: Brookes.

Graham, S. \& Harris, K. (2003). Students with learning disabilities and the process of writing: A meta-analysis of SRSD studies. In H. L. Swanson, K. R. Harris, \& S. Graham (Eds.), Handbook of Learning Disabilities (pp. 323-344).

Graham, S., \& Harris, K. R. (2000). The role of self-regulation and transcription skills in writing and writing development. Educational Psychologist, 35, 3-12.

Graham, S., \& Harris, K. R. (1997). It can be taught, but it does not develop naturally: Myths and realities in writing instruction. School Psychology Review, 26, 414424. 
Graham, S. \& Harris, K. R. (1993). Self-regulated strategy development: Helping students with learning problems develop as writers. The Elementary School Journal, 94, 169-181.

Graham, S. \& Harris, K. (1989). Components analysis of cognitive strategy instruction: Effect on learning disabled students' compositions and self-efficacy. Journal of Educational Psychology, 81, 353-361.

Graham, S., Harris, K., MacArthur, C., \& Schwartz, S. (1995). Effects of goal setting and procedural facilitation on the revising behavior and writing performance of students with writing and learning problems. Journal of Educational Psychology, $87,230-240$.

Graham, S., Harris, K. R., \& Reid, R. (1992). Developing self-regulated learners. Focus on Exceptional Children, 24, 1-16.

Graham, S. \& Perin, D. (2006, October). Writing next: Effective strategies to improve writing of adolescents in middle and high schools. A report to Carnegie Corporation of New York. Washington, DC: Alliance for Excellent Education.

Graham, S. \& Perin, D. (2007). A meta-analysis of writing instruction for adolescent students. Journal of Educational Psychology, 99, 2007.

Gualtieri, C.T., \& Johnson, L.G. (2006). Efficient allocation of attentional resources in patients with ADHD: Maturational changes from age 10 to 29. Journal of Attention Disorders, 9, 1-9.

Hamlett, K. W., Pelligrini, D. S., \& Conners, C. K. (1987). An investigation of executive processes in the problem-solving of attention deficit disorder-hyperactive children. Journal of Pediatric Psychology, 12, 227-240. 
Harris, K. \& Graham, S. (1999). Programmatic intervention research: Illustrations from the evolution of self-regulated strategy development. Learning Disability Quarterly, 22, 251-262.

Harris, K. \& Graham, S. (1996). Making the writing process work: Strategies for composition and self-regulation. Cambridge, MA: Brookline.

Harris, K., Graham, S., \& Mason, L. (2003). Self-regulated strategy development in the classroom: Part of a balanced approach to writing instruction for students with disabilities. Focus on Exceptional Children, 35, 1-16.

Hayes J.R., \& Nash J.G. (1996). On the nature of planning in writing. In C.M. Levy \& S. Ransdell (Eds.) The Science of Writing. (pp. 29-55). Mahwah: LEA

Jacobson, L. T. \& Reid, R. (in press). Self-regulated strategy development: Improving the persuasive essay writing of high school students with ADHD. Exceptional Children.

Kazdin, A. E. (1982). Single case research designs: Methods for clinical and applied settings. New York: Oxford University Press.

Kliegel, M. Ropeter, A., \& Mackinlay, R. (2006). Complex prospective memory in children with ADHD. Child Neuropsychology, 12, 407-419.

Kofman, O., Larson, J. G., \& Mostofsky, S. H. (2008). A novel task for examining strategic planning: Evidence for impairment in children with ADHD. Journal of Clinical and Experimental Neuropsychology, 30, 261-271.

Lee, S. S., \& Hinshaw, S. P. (2006). Predictors of adolescent functioning in girls with attention deficit hyperactivity disorder (ADHD): The role of childhood ADHD, 
conduct problems, and peer status. Journal of Clinical Child and Adolescent Psychology, 35, 356-368.

Lienemann, T. O., Graham, S., Leader-Janssen, B., \& Reid, R. (2006). Improving the writing performance of struggling writers in second grade. The Journal of Special Education, 40, 66-78.

Lienemann, T. O. \& Reid, R. (2008). Using self-regulated strategy development to improve expository writing with students with attention deficit hyperactivity disorder. Exceptional Children, 74, 1-16.

MacArthur, C., Graham, S., \& Schwartz, S. (1991). Effects of reciprocal peer revision strategy in special education classrooms. Learning Disability Research and Practice, 6, 201-210.

MacArthur, C. A., \& Graham, S. (1987). Learning disabled students' composing under three methods of text production: Handwriting, word processing, and dictation. The Journal of Special Education, 21, 22-42.

Mayes, S. D., Calhoun, S. L. \& Crowell, E. W. (2000). Learning disabilities and ADHD: Overlapping spectrum disorders. Journal of Learning Disabilities, 33, 417-424.

Messina, L. d. F., Tiedemann, K. B., de Andrade, E. R., \& Primi, R. (2006). Assessment of working memory in children with attention-deficit/hyperactivity disorder. Journal of Attention Disorders, 10, 28-35.

MTA Cooperative Group. (1999). A 14-month randomized clinical trial of treatment strategies for attention deficit/hyperactivity disorder. Archives of General Psychiatry, 56, 1073-1086.

National Assessment of Educational Progress. (2008). 
National Center for Education Statistics. (1998). Nation's report card: Writing 1997.

Washington, DC: U.S. Government Printing Office.

National Center for Education Statistics. (2007). Nation's report card: Writing 2006.

Washington, DC: U.S. Government Printing Office.

National Commission on Writing for America's Families, Schools, and Colleges. (2004,

September). Writing: A ticket to work...or a ticket out. New York: College

Entrance Examination Board.

Nippold, M. A., Ward-Longergan, J. M., \& Fanning, J. L. (2005). Persuasive writing in children, adolescents, and adults: A study of syntactic, semantic, and pragmatic development. Language, Speech, and Hearing Services in Schools, 36, 125-138.

O’Neill, M. \& Douglas, V. I. (1991). Study strategies and story recall in Attention Deficit Disorder and reading disability. Journal of Abnormal Child Psychology, 19, 671692.

O’Neill, M. E. \& Douglas, V. I. (1996). Rehearsal strategies and recall performance in boys with and without attention deficit hyperactivity disorder. Journal of Pediatric Psychology, 21, 73-88.

Peter D. Hart Research Associates, Inc. \& Public Opinion Strategies. (2005). Rising to the challenge: Are high school graduates prepared for college and work? Prepared for Achieve, Inc. Washington, DC: Author.

Purvis, K. L., \& Tannock, R. (1997). Language abilities in children with attention deficit hyperactivity disorder, reading disabilities, and normal controls. Journal of Abnormal Child Psychology, 24, 133-144. 
Re, A. M., Pedron, M., and Cornoldi, C. (2007). Expressive writing difficulties in children described as exhibiting ADHD symptoms. Journal of Learning Disabilities, 40, 244-255.

Reid, R. (1996). Self-monitoring for students with learning disabilities: The present, the prospects, the pitfalls. Journal of Learning Disabilities, 29, 317-331.

Reid, R. \& Lienemann, T. O. (2006a). Improving the writing performance of students with ADHD. Exceptional Children, 73, 53-68.

Reid, R. \& Lienemann, T. O. (2006b). Strategy instruction for students with learning disabilities. New York: The Guilford Press.

Reid, R., Trout, A., \& Schartz, M. (2005). Self-regulation of interventions for children with attention deficit/hyperactivity disorder. Exceptional Children, 71, 11311138.

Resta, S., \& Eliot, J. (1994). Written expression in boys with attention deficit disorder. Perceptual \& Motor Skills, 79, 1131-1138.

Rogers, L. \& Graham, S. (2008). A meta-analysis of single subject design writing intervention studies. Journal of Educational Psychology, 100, 879-906.

Rucklidge, J. J., \& Tannock, R. (2001). Psychiatric, psychosocial and cognitive functioning of female adolescents with ADHD The Journal of the American Academy of Child and Adolescent Psychiatry 40, 530-540.

Saddler, B. (2006). Increasing story-writing ability through self-regulated strategy development: Effects on young writers with learning disabilities. Learning Disability Quarterly, 29, 291-305

Saddler, B., Moran, S., Graham, S., \& Harris, K. R. (2004). Preventing writing 
difficulties: The effects of planning strategy instruction on the writing performance of struggling writers. Exceptionality, 12, 3-17.

Scardamalia, M., \& Bereiter, C. (1986). Written composition. In M. Wittrock (Ed.), Handbook of research on teaching ( $3^{\text {rd }}$ ed., pp. 778-803). New York: MacMillan.

Scruggs, T. E., \& Mastropieri, M. A. (1998). Summarizing single-subject research: Issues and applications. Behavior Modification, 22, 221-242.

Scruggs, T. E., Mastropieri, M. A., \& Casto, G. (1987). The quantitative synthesis of single-subject research: Methodology and validation. RASE: Remedial \& Special Education, 8, 24-33.

Skilos, S. \& Kerns, K. A. (2004). Assessing multitasking in children with ADHD using a modified Six Elements Test. Archives of Clinical Neuropsychology, 19, 347-361.

Shallice, T., Marzocchi, M. Cosner, S., Del Savio, M., Meuter, R. F. \& Rumiati, R. I. (2002). Executive function profile of children with attention deficit hyperactivity disorder. Developmental Neuropsychology, 21, 43-71.

Tannock, R., \& Schachar, R. J. (1996). Executive dysfunction as an underlying mechanism of behavior and language problems in attention deficit hyperactivity disorder. In J. H. Beichtman, N. Cohen, M. M. Konstantareas, \& R. Tannock (Eds.), Language, Learning, and Behavior Disorders: Developmental, Biological, and Clinical Perspectives (pp. 128-155). New York: Cambridge University Press.

Tannock, R., Purvis, K. L., \& Schachar, R. J. (1993). Narrative abilities in children with attention deficit hyperactivity disorder and normal peers. Journal of Abnormal Child Psychology, 21, 103-117.

Tant, J. L. \& Douglas, V. I. (1982). Problem-solving in hyperactive, normal, and reading- 
disabled boys. Journal of Abnormal Child Psychology, 10, 285-306.

Toplak, M., Jain, U., \& Tannock, R. (2005). Executive and motivational processes in adolescents with Attention-Deficit-Hyperactivity Disorder (ADHD). Behavioral and Brain Functions, 1, 1-8.

Troia, G. A. \& Graham, S. (2002). The effectiveness of a highly explicit, teacher-directed strategy instruction routine: changing the writing performance of students with learning disabilities. Journal of Learning Disabilities, 35, 290-305.

U.S. Department of Education, National Center for Education Statistics (2006).

U.S. Department of Education, National Center for Education Statistics. (2007).

Waschbusch, D. A., Craig, R., Pelham, W. E., \& King, S. (2007). Self-handicapping prior to academic-oriented tasks in children with Attention Deficit/Hyperactivity Disorder (ADHD): Medication effects and comparison with controls. Journal of Abnormal Child Psychology, 35, 275-286.

Weiss, G., \& Hechtnian, L. T. (1993). Hyperactive children grown up: ADHD in children, adolescents, and adults (2nd edition). New York: Guilford Press.

Wechsler, D. (2001) Wechsler individual achievement test (2nd ed.). San Antonio: The Psychological Corporation

Zelazo, P. D. \& Jacques, S. (1997). Children's rule use: Representation, reflection, and cognitive control. Annals of Child Development, 12, 119-176.

Zentall, S. S. (1986). Effects of color stimulation on performance and activity of hyperactive and nonhyperactive children. Journal of Special Education, 78, 159165. 
Zentall, S. S. (2005). Theory- and evidence-based strategies for children with attentional problems. Psychology in the Schools, 42, 821- 836.

Zimmerman, B. J. (2001). Theories of self-regulated learning and academic achievement: An overview and analysis. In B. J. Zimmerman \& D. H. Schunk (Eds.), Selfregulated learning and academic achievement: Theoretical perspectives (2nd ed.). (pp. 1-37). Mahwah: Lawrence Erlbaum Associates Publishers. 
Appendix A

\section{Nebraska Lincoln}

\section{DEPARTMENT OF SPECIAL EDUCATION} AND COMMUNICATION DISORDERS

Dear Parent,

At the University of Nebraska we are committed to improving the quality of instruction for children with ADHD. As a part of this process we will be starting a project to try to improve the quality of student writing. The project has been approved by Lincoln Public Schools and by your child's school. We will do this by teaching students a specific strategy that we believe will improve their essay writing skills. The strategy has been used with other students and has been shown to help students to plan their essays, organize their essays, and write longer and better essays.

If you choose to allow your son or daughter to participate in the study this is what will occur. First, your son or daughter will also be pre-tested to determine whether or not he or she qualifies for the study. This will take around one hour. Only students who have difficulties in written expression will qualify. Second, if your son or daughter qualifies, they will receive instruction in a strategy designed to help them write better stories. The strategy instruction program involves eight 30-minute lessons. All instruction will be done by specially trained graduate students. Instruction will take place during times scheduled by the school. Finally, after instruction we will do a post-test to assess improvements. We need to collect demographic and academic achievement information on your child. We will also need to talk with you briefly about how your child was diagnosed with ADHD and whether or not they receive medication.

We want to stress that NO INFORMATION THAT COULD IDENTIFY YOUR CHILD WILL BE GIVEN OUT. At the end of the project when results are available, you will be given the opportunity to see the results of using the strategy. If you have any questions or need additional information please feel free to contact us.

If you wish to allow your child to participate in the study, please fill out the enclosed consent form and return it to us in the enclosed envelope.

Thank you,

Laura T. Jacobson and Bob Reid 


\section{Informed Consent Form}

Identification of Project: Improving the writing performance of children with ADHD

Your child was identified as a possible participant in this project because he or she has been diagnosed as having ADHD, and was identified as a struggling writer by your child's teacher.

\section{Purpose of the Research:}

This research project will investigate the effectiveness of a writing strategy on improving the writing of students with ADHD. The intent is for your child's writing to become more organized, the writing topics elaborated, and the essays more detailed.

\section{Procedure:}

Initially, your child will be given a writing assessment to determine eligibility. If he or she is eligible, participation in this study will take approximately 6 weeks of your child's time. Your child will receive 30 minutes of individual instruction 3 days/week for 3 weeks. First, your child will be asked to write essays to determine the current level of writing performance. After this pre-testing, your child will receive instruction in the use of an essay writing strategy. When this instruction ends ( 8 sessions), your child will be asked to complete the assessments again. We would also like permission to review your child's school records for information on academic achievement levels, medication prescribed, and other testing. We will also conduct a brief phone interview to ask you how your child was identified as having ADHD, who made the diagnosis, when the diagnosis was made, whether or not your child is prescribed medication for ADHD, and if so, what medication.

\section{Risks and/or Discomforts}

Participation in the study poses no known risk to participants, as all assessment and instructional practices are part of normal instructional practices used in classrooms.

\section{Benefits}

The potential benefits of this study for your child include possible improvements in the quality of their written expression. In addition, we hope to inform other researchers and practitioners of the benefits of this instructional procedure. 


\section{Confidentiality}

Any information gathered during this study, which may identify your child, will be kept strictly confidential. All data from assessments will be anonymously recorded for analysis to protect your child from identification. Any qualitative or descriptive data used in professional articles or presentations will be done using pseudonyms.

\section{Compensation}

There will be no compensation for participating in this research.

\section{Opportunity to Ask Questions:}

You may ask questions before, during or after this experiment by contacting either Laura Jacobson (613-4940) or Robert Reid (472-5816). Sometimes study participants have questions or concerns about their rights. In that case you should call the University of Nebraska-Lincoln Institutional Review Board at (402) 472-6965.

\section{Freedom to Withdraw:}

You are free to decide not to participate in this study. You can also withdraw at any time without affecting your relationship with the investigator, your child's school, and the University of Nebraska-Lincoln. Your decision will not result in any loss of benefits to which you are otherwise entitled.

\section{Consent, Right to Receive a Copy:}

You are voluntarily making a decision whether or not to allow your child to participate in the research study. Your signature certifies that you have given permission for your child to participate, having read and understood the information presented. You will be given a copy of this consent form to keep.

Child's name - printed

Signature of parent/guardian

date

Name and Phone numbers of Investigators

Error! Contact not defined.

(402) 613-4940

Robert Reid

(402) $472-5816$ 


\section{Nebraska Lincoln}

\section{DEPARTMENT OF SPECIAL EDUCATION} AND COMMUNICATION DISORDERS

\section{Child Assent Form}

Improving the writing performance of children with ADHD

We would like to invite you to take part in this research study. We are asking you because your teacher thought our program would help you write better.

We are interested in the writing skills of high school students, and what kind of teaching will help them be better writers. We are starting a special project at your school and would like your help. We want to teach you how to write better essays. By working on this special project with us, you will help us know if this kind of teaching could help other students write better essays.

You will get to work with us on writing essays. We will work together 3 days a week, for about four weeks. Your classroom teachers will let you know when we will be there.

Your parents have already given their permission for you to take part in this study. Please talk this over with your parents before you decide whether or not to participate. You do not have to be in this study if you do not want to. If you decide to participate in the study, you can stop at any time. If you have any questions at any time, please ask us.

Does this sound like something that you would like to do? If so, sign the bottom of this letter.

IF YOU SIGN THIS FORM IT MEANS THAT YOU HAVE DECIDED TO PARTICIPATE AND HAVE READ EVERYTHING THAT IS ON THIS FORM. YOU AND YOUR PARENTS WILL BE GIVEN A COPY OF THIS FORM TO KEEP.

Signature of participant

Date

Signature of investigator

Date

INVESTIGATORS

Laura Jacobson.

(402) 613-4940

Robert Reid

(402) $472-5816$ 
Appendix B

Parent Interview Form

1. How old was the child when they were identified as having ADHD?

2. How make the diagnosis? (not a name: pediatrician, psychiatrist, other?)

3. Is the child prescribed medication for ADHD? If so, what? 


\section{Appendix C}

Essay Prompts

Across the country school systems are beginning to use a year round school model. LPS is looking into the idea of going to school year round. Your school newspaper asks you to present your view in the paper.

Write an essay answering the following questions: Do you think students should have to go to school in the summer?

Not all teachers give homework. Your teacher tells the class that she will decide whether or not to give homework based on your suggestion.

Write an essay answering the following question: Do you think teachers should give homework?

Many teenagers argue with their parents about keeping their room clean. What do you think?

Write an essay answering the following question: Do you think kids should be required to clean their room?

Because of safety concerns, a number of states are considering changing the driving age to 18 . The hope is to eliminate many of the teenage driving deaths.

Write an essay answering the following question: Do you think the driving age should be changed to 18 ?

The PTO is having a meeting about parenting. They would like the views of a high school student represented in their discussion. They have asked you to come to speak on the evening's topic.

Write an essay answering the following question: Do you think parents should decide who your friends are

The nutrition of school lunches is a big topic these days. As a student of the public schools you've been asked for your opinion.

Write an essay answering the following question: Should children be allowed to eat whatever they want?

Your younger sister wants a gerbil. Your father says no way. Your mom hasn't made up her mind about it yet.

Write an essay answering the following question: Should kids be allowed to have their own pets?

Grades are a big part of school. As a high school student do you feel parents should give their children money for having good grades on their report card?

Write an essay answering the following question: Should parents give their children money for having good grades on their report cards? 
When I was in high school my parents made me turn my light off by $10 \mathrm{pm}$ on school nights. Many of my friends were aloud to stay up late.

Write an essay answering the following question: Should teenagers be allowed to choose their own bedtimes on school nights?

Some people in Lincoln have put an idea before the school system asking to have the school day shortened.

Write an essay answering the following question: As a student in Lincoln, do you think the school day should be shorter?

Most of the courses that are taken in high school are required to graduate. There is only time for a few electives.

Write an essay answering the following question: Should students be able to choose the things they study in school?

There are many opposing views about punishing kids when they do something wrong.

Write an essay answering the following question: Do you think kids should be punished when they do something wrong?

Television is a part of most children's daily life. Many kids watch 2 or more hours a day.

Write an essay answering the following question: Should children be allowed to choose the television shows they watch?

A couple you know has 1 child and is considering having more. They ask for your opinion.

Write an essay answering the following question: Is it better to be an only child or to have brothers and sisters?

Lincoln public schools are trying to decide if computer classes should be required for students in every grade $\mathrm{k}-12$. As a member of the student body they ask you to speak on the subject.

Write an essay answering the following question: Should kids be required to learn how to use computers?

Many kids today are involved in sports, many starting at a very young age. Parent involvement in children's sports often is discussed in the news.

Write an essay answering the following question: Should parents coach their children's teams? 
Many high school students have jobs. Federal law limits students to working no more than 3 hours on a school day and not after 7 pm during the school year.

Write an essay answering the following question: Should teenagers be allowed to work longer hours during the school year?

In Chicago and Boston there has been discussion of having some classes that are divided up into only boys and only girls.

Write an essay answering the following question: Should boys and girls be taught in separate classes in school?

Many people look to their favorite athletes as heroes. They look to them as models of what and who they want to be as adults.

Write an essay answering the following question: Should sports stars be treated as heroes?

As a person under 18, you are not able to participate in the government though voting. Some people think that should change.

Write an essay answering the following question: Should kids your age should be able to vote?

Many schools require students to volunteer for 20 or more hours before they graduate.

Write an essay answering the following question: Should high school students be required to do volunteer hours to graduate?

Many public schools on the East coast require students to wear uniforms. The school board is interested in the idea and has asked you to come give your opinion.

Write an essay answering the following question: Should students be required to wear uniforms to school? 
Appendix D

\section{Essay Elements Scoring Rubric - Coding Sheet}

Student:

Coder:

Date:

Prompt letter:

Essay and phase number:

\section{Number of Essay Elements}

$\square$ Topic Sentence

$\square$ Three reasons introduced in introduction

$\circ$ Reason 1
$\circ$ Reason 2
$\circ$ Reason 3

$\square$ Paragraph supporting reason 1

$\square$ Paragraph supporting reason 2

$\square$ Paragraph supporting reason 3

$\square$ Rejects argument for the opposite side

$\square$ Concluding paragraph 
Appendix E

\section{Stop and Dare}

Lesson 1

\section{Lesson Overview}

The essay planning and essay parts reminder will be introduced in this lesson. The teacher will introduce the parts of the persuasive/opinion essay planning strategy, STOP. Collaboratively the teacher and students will brainstorm, discuss, and list the parts of a well-written essay. The teacher will describe the parts of the essay parts reminder, DARE. Students and teacher will establish goals for using STOP and DARE: "To write better essays with 7 parts."

\section{Student Objectives}

Student will orally state the parts of the essay planning strategy STOP. Students will orally state the parts of a good essay as in DARE. Student will identify essay parts included in a sample essay and one of their baseline essays. Student will graph the number of parts found in their own essay.

\section{Materials}

STOP AND DARE MNEMONIC CHART (CHART), STOP AND DARE BRAINSTORMING SHEET (BRAINSTORM), sample essays for identifying parts, previously written individual student essays, chart paper or chalkboard, pencils

\section{Set the Context for Student Learning}

Introduce writing essays. This introduction to the strategy emphasizes what makes a good essay. Explain to the students that for this writing class they will learn how to compose good essays. Good essays can persuade someone to change her or his point of view. Good writers plan before they write. Good essays have several parts.

"I know that you've had to write essays for your classes over the last few years. Writing essays is difficult and over the next few weeks I am going to be teaching you a trick to help you compose a good essay. Good essays can persuade someone to change his or her point of view. Good writers plan before they write and good essays have a few basic parts."

Why should students learn to write essays? The basic ideas in essays are found everywhere: on TV, radio, newspaper editorials, government meetings, political rallies, letters to the editor, at home, etc. People who can write good essays know how to convince and persuade others. Students can share if they have tried to convince their parents, teachers, or friends to believe their side of an issue before, and what those issues 
were. Make note of the LPS essay requirement for the GDE and the NE state writing tests. 
"What is one reason that someone has to learn to write an essay? (Respond positively to any logical answer or acknowledge the student's response and go on.) People who can write good essays know how to convince and persuade others. I'm sure you've tried to convince one of your parents or teachers to believe your side of an issue before. Tell me about 1 time you tried to convince someone of your position before. (Respond positively to student answers. If no answer, provide an example of your own.) So, we know that we need to know how to convince others. We often need to do this in essays too. Here in Lincoln you have to be able to write a persuasive essay for your GDE and in $11^{\text {th }}$ grade you have to write one for the state exam."

\section{Develop the Strategy and Self-Regulation}

\section{Step One - Describe and Discuss the Strategy: STOP}

In this first step of instruction the teacher should discuss the writing process with the student, emphasizing that most "expert" writers plan before starting to compose.

- Give the student the STOP AND DARE CHART. Explain that the chart will help them learn and remember the planning process they will be learning. The CHART should be covered so that only the first step, "Suspend Judgment," shows.

Say, "What does suspend mean? I know that if I got suspended from school I wouldn't be allowed to come to school. So, if I suspend judgment what might that mean? (Respond positively to correct answers. Acknowledge incorrect responses by explaining what suspend means.) Good, so suspend means to put aside, but only temporarily. If I'm suspended I get to go back to school eventually right? The second word is judgment. In this case, we need to remember that "judgment" in this case means keeping your mind open to both sides of an issue. During this part of our strategy you will brainstorm ideas for AND against the assigned topic. We need to suspend judgment so we are able to come up with as many ideas for both sides as possible. If I've already made a decision I might not be able to see all the arguments for both sides."

- Uncover "Take a Side."

"In this step you will evaluate what you've brainstormed up to this point. You need to look at both sides of the issue, the arguments that you have for each side, and make a decision about which side you believe it. This is an important part of the planning process. Why might it be important to take a side BEFORE you start to plan? (It will help you pick the ideas that you will use in your essay.) Okay, so once you have chosen a side to support you will need to try to convince your reader to agree with you. You'll use the ideas that you brainstormed to help you make your point." 
- Uncover "Organize Ideas." The third step will help students to select ideas they feel will support their belief, and to select at least one argument they can refute.

"In this step you will pick ideas that you feel will support your belief. Additionally, you'll pick one argument that you can refute. Refute means that you have to be able to oppose it, shoot it down, but with support. "That argument is stupid" doesn't work here. For a persuasive essay to be strong it needs to have supporting ideas as well as explanations of the counter arguments. These counterarguments have to be dealt with carefully. We want to show that they ARE NOT the side people should believe or our readers might think it is better than our REAL argument. How might we be able to refute an argument that goes against our point? (thinking of a contrasting reason or a condition that would make an exception to the argument. ) Why is that important? (need to show that idea isn't good or not as good as ours)

Now I want you to select 3 ideas for the side you're supporting and 1 from the side that you're refuting. Number the arguments from 1-3 in the order you think they should be presented in your essay. This will help you organize your essay. Deciding the order of your arguments is similar to using a map. Why do we use a map when we travel? What purpose does it serve?" When a traveler uses a map, he or she looks first for her or his destination and chooses a route to that place. Taking a side is like deciding your destination, and your essay will guide others to accept the side you believe in."

- Uncover "Plan More as You Write."

"Plan More as You Write means that while you're writing you should still be thinking about your arguments for and against the topic. Your plan is a guide but it can change. If you come across roadwork when you're traveling you don't just stop and wait until it's done. You take a detour. Writing can be like that too. Maybe you realize one of your ideas isn't as strong as you thought or maybe your thought of something new to add. You might come up with a great idea while you're writing. You just need to be sure it clearly relates to your position."

\section{Step Two - Parts of an Essay}

In this step the teacher and student will brainstorm parts of a good essay.

- "What are the parts of a good essay? What words have you learned or heard your teachers use when they talk about good essays? (Respond positively to all student answers; write down any answers that correspond to the essay parts below, such as main idea, reasons, examples, arguments, end, etc. Prompt as necessary)." 
- "When we talk about essays and the parts that make up an essay there are certain words that we should use. I want you to use these words and get used to them if you aren't already. These words are - topic sentence, supporting ideas, argument(s), and conclusion. (Write these parts on the chart paper or chalkboard as you label each. Make sure these terms are clearly understood by the student. Note any parts that students have previously generated.)

\section{Step Three - Essay Parts Reminder: DARE}

This step will introduce students to the essay parts reminder DARE.

- Give the sample essay to the student.

"I want you to read along silently as I read the essay aloud. Raise your hand when you hear the topic sentence, supporting ideas, arguments, and conclusion. (Respond positively \& provide encouragement as you go along)."

- After all the essay parts have been identified, ask for another example of each part for the same topic (for example, an opposing premise). (Write down student responses on chart paper or chalkboard.)

"Now I'm going to show you a reminder to help you remember the four essay parts. We'll practice using it but remember, you need to memorize it."

- Uncover the essay part reminder DARE chart \& read it aloud:

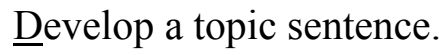

Add supporting ideas.

$\underline{\text { Reject an argument. }}$

End with a conclusion.

\section{Step Four - Chart Current Level of Performance}

The students' current level of performance will be reviewed in this step. If time is running short, however, proceed to step five and complete this step during the next session.

"Remember the purpose of knowing a strategy is to help you become a better writer. Right now were going to set some goals for writing a good essay."

- Hand out one of the pretest (baseline) essays.

"This is one of the essays that you wrote for me before we started meeting together. We're going to read it together and see which parts of a good essay you included and which ones you didn't. I'm going to read it aloud, as I do, raise your hand if hear or see one of the essay parts we just talked about. Okay?" 
- Briefly note which parts each student has and what is missing.

"Okay, lets underline all the essay parts that you included and make a list of those that are missing. This gives a good idea about what we need to work on. (note included and excluded parts). Now we're going to graph how many essay parts we included, along with the number of words that were used in your essay. We are looking at how long your essay is too because we know that often, a longer essay is a better essay. We're going to use this to keep a running record of your improvement. That means we'll do this each time that you write an essay."

- Note also that even if a part is present, students may be able to make that part better the next time. Give examples such as:

- can tell your point of view

- can have several reasons

- can give examples

- can consider an argument

- can reject an argument by countering it or dealing with it in some way

- can have a clear ending

- Spend a few minutes explaining the STOP AND DARE CHECKLIST. Give the student a CHECKLIST and ask him/her to mark the number of essay parts written in their pretest.

- Explain the goal - to write better essays. Remind them that good essays have all STOP and DARE parts, and that good essays make sense. The goal is to have all the parts and "better" parts next time.

- Have them set a goal for the next time they write and note the goals on the graphing sheet (length \& essay parts).

\section{Step Five- Practice STOP and DARE}

In each lesson student will practice the mnemonics and parts of STOP and DARE. This will continue until the teacher is certain that both the mnemonic and parts are remembered automatically.

- Practice the mnemonic STOP.

"It is important that you memorize this so you don't have to think about it to use it. If it is memorized you can use it automatically and just think about the assignment you're working on rather than the parts of the reminder."

- Turn over the CHART and ask the student to tell you the essay-planning reminder. (They should tell you: STOP, and tell you what each letter means.) Ask the student to write the reminder on paper. If student has trouble, turn the CHART over 
and allow them to look. Keep doing this until all students can tell you the reminder and explain each letter from memory.

- Practice the essay parts. Ask the student to explain the parts. (Turn over the CHART, and ask students to tell you the "essay parts reminder.") Ask each student to write the reminder on paper. If students have trouble, turn the CHART back over and allow them to look. Help students as needed. Do this until you feel sure that the student knows what all the parts are.

\section{Wrap-Up}

Give the student a reminder sheet to keep with them. Announce that there will be a nongraded test in the beginning of the next writing class.

"I will ask you the essay planning and essay parts reminders." 


\section{STOP and DARE}

Lesson 2

\section{Lesson Overview}

The essay planning and essay parts reminder will be reviewed in this lesson. The teacher and students will collaboratively identify parts and elaborations in an essay that is read in class. The teacher will model using the strategy with cue cards. The students will rehearse the strategy using the cue cards.

\section{Student Objectives}

The students will verbally state the part of the essay planning strategy STOP and the parts of a good essay as in DARE. The students will demonstrate an understanding of how to use the cue cards.

\section{Materials}

STOP AND DARE CUE SHEET (DIRECTIONS), STOP AND DARE BRAINSTORMING SHEET (BRAINSTORM), sample essays for identifying parts, previously written individual student essays, chart paper or chalkboard, pencils

\section{Set the Context for Student Learning}

Test the students to see if they remember the word that will help them remember how to plan (STOP) and what the letters stand for. Give them a piece of paper and ask them to write down the word. Ask students to tell you what each word/phrase means. Help as necessary. Test to see if they remember the word that will help them remember the parts of a good essay (DARE). Give them a piece of paper and ask them to write down the word. Ask students to tell you what each word means. Help as necessary. 


\section{Develop the Strategy and Self-Regulation}

\section{Step One - Identify Essay Parts and Elaborations}

- Give the sample essay to the student.

"Here is another sample essay like we looked the last time we met. Read along as I read aloud. Let me know when you hear each of the essay parts. (Underline each in the text as they are identified). Now that we found all the parts included in this essay I want us to think about other examples of each essay part. It is important to notice that good writers often elaborate their reasons, topic sentence, argument, and conclusions. These elaborations provide support for the reasons, arguments, etc. Lets look back at the two essays that we've already read and see how the authors did this. (Have an example from each essay already identified)."

\section{Step Two - Model the Strategy}

In this step the teacher will model how to use the strategy to plan and write a good essay. It is important that the teacher has memorized the procedure so that it will be fluent. In order to provide an example of modeling this strategy, a sample script has been provided below.

- Keep the STOP and DARE CHART to the side, you will use CUE CARDS during modeling.

"Today, I am going to show you how to use STOP and DARE together to plan and write a good essay. I will talk out loud as I go. You might be able to help me, if I ask you, but what I really want you to do is to listen and watch me work. This might seem sort of strange but I want you to listen and watch closely so you get the idea as to how I use this strategy to write my essay. It will make it easier for you to understand how to think your way through the strategy."

- Model the entire process using the CUE SHEET and the list of TRANSITION WORDS. Follow the steps and statements below, using ideas generated for the model essay.

'OK, first I need to 'suspend judgment.' That means don't make up my mind about the topic yet. I need to brainstorm ideas for and against my topic. I need to have my ideas ready before I make any decisions about which side I'm going to take. I know that by not taking a side now I'll be better at finding arguments for both sides. I'm going to write my ideas on this BRAINSTORM sheet. I like that there are columns, plus, my STOP reminder is listed right 
there if I need it. This will definitely help me keep my ideas organized while I plan."

- Write two or three ideas for one side and one or two ideas for the other side on the BRAINSTORM sheet.

- Refer to the CUE SHEET.

"I'm going to use my cue sheet now, to help me plan. There are three questions listed with Suspend Judgment. These must be things I need to think about before I move on to the next step. I'll go through them one at a time to be sure I'm following all the steps. The first question says, 'Did I list ideas for both sides? If not, do this now.' Let me see... I did that!."

"OK. What does the second question say? 'Can I think of anything else? Try to write more.' All right, I need to think of more reasons. What other reasons can I think of?" (Add at least one idea to the FOR side.) "What about AGAINST? Why wouldn't I support this idea?"( [PAUSE], then, add another idea to the AGAINST side. Add one more idea to one side )“Ok, do those make sense? Are they listed on the right side? Yes? Okay what's next?"

[PAUSE] "One more question for this step. It says, 'Another point I haven't yet considered is...Think of possible arguments.' Do I have any arguments? Yes, I do. [PAUSE] OK, are there any points I haven't considered yet?" [PAUSE] "This is a hard because I have so many ideas already. I need to take my time and think of something someone else would say." Add at least one idea, preferably for the side that you will take.

- $\quad$ Step 2 - Take a Side

"Wow, that's great. I'm done with step 1 and have done a lot of good work. Now I need to do step 2, 'Take a Side'. That means I really have to pick one side as my argument. Which one do I really believe?" Provide answer. "I think this is the right one to choose because I think it is right based on my opinion."

[PAUSE] Let me see what the cue sheet for step 2 says. It says, 'Place a + at the top of one box to show the side you will take in your essay. Okay, I chose this side so I'll write my + up here. Okay, have I done everything for that step? Let me look back at my cue sheet and see. Yes, I have. Good. I'm halfway done. What's next? 
- $\quad$ Step 3, "Organize ideas.

“Step 3 is 'Organize ideas'. It says I should decide which ideas are strong and which ideas I can dispute. That means I should think about the ideas I have for my argument." Read each idea that is on the side you have chosen aloud and decide if it is a good idea. Be sure to verbalize why you think an idea is or is not strong enough to use. You should note at least one idea that is not strong, decide out loud to skip it, and explain why it is being skipped (i.e., I don't know enough about it, it isn't clear etc.)

"OK, now I have strong ideas for my argument. I need to decide which ideas can dispute. That means I need an argument that I can reject, one that I know how to deal with in some way. I have to be able to make my reader see why I think the argument isn't as good an idea as the one I've chosen." Choose one argument from the reasons on the other side. [PAUSE] Choose one more argument. "I have to choose my arguments carefully so I don't confuse my reader about which side I am on. I'm really doing well with this plan. I like my ideas - let me look at the cue sheet for this step. It says, 'Put a star next to ideas you want to use.' I need to choose at least 3 ideas to use that support my point. I'll start with 3 but I know that I can always choose more if I think I can support them and they make sense. [Make choices of which arguments to use. Put a star next to them.] Okay I picked 3 that I think are the strongest. What is my next step? Let me look at my cue sheet."

"What does the second Organize Ideas direction say? 'Did I star ideas on both sides? Choose at least one argument you can dispute.' Well I decided that I had two arguments that I can dispute. I'll pick the one I think is the easiest. Last direction for step 3. It says, 'Number your ideas in the order you will use.' [Pause] I'd better think about this - what makes sense? I need to remember that the order of these will help guide my reader so they agree with what I believe. It's like the map we talked about earlier. I have to remember that the point of this essay is to make the reader agree with me. This should help."

"This is going to be a good essay, I'm really taking my time to plan it out. The last step is, 'Plan more as you write. Remember to use all four essay parts and continue planning.' OK, that means I should still think of ideas as I write my essay. Let me look at my cue sheet and see what I need to think about next."

"Well, I already finished all the STOP steps. Nice, I'm making progress.! The next thing listed on my cue sheet is DARE. That means I'm ready to start actually writing this essay. I know what DARE means [Read cue]. So, I'm ready to write my essay, I'll just think of DARE as I go." 
- Verify each part that you write by telling that you have your topic sentence, etc. Point out that you can add supporting ideas after you reject your argument. Use cohesive words sparingly, at key places, such as when you refute and argument or with a group of related ideas.

- Be sure to elaborate on 2 or 3 ideas as you write, and try to revise something as you go. Give a strong, summative conclusion by restating your premise using different words.

- After you finish, compliment yourself for the work you have done and then demonstrate graphing. Mark the CHECKLIST for each part, write down the number of ideas selected on the line under the column. If you met a goal over three, you "busted" the chart and can draw a star on top of the column. Thank the students for their help (which may have simply been to pay attention).

\section{Step Three - Rehearsal of STOP and DARE}

Students should verbally rehearsal of STOP and DARE until mastery has been achieved. Students must be able to recite all steps and essay parts from memory. Wording doesn't have to be exact, but meaning should be apparent.

- Review 4 steps - read STOP off chart as you go. Tell students they need to memorize steps.

- Have students practice. Practice any way you think helpful. Read with cue sheet facing up, turn sheet, write, cover, say, repeat, etc.

- Students can paraphrase 4 steps and DARE from memory.

- Students can paraphrase at least half of the ESSAY PARTS from memory. Tell students they will be able to memorize all the cards after they get a chance to compose an essay tomorrow.

\section{Wrap-Up}

Remind students that you will check next time to see if they can remember on their own the essay planning reminder (STOP) and the essay parts reminder (DARE). 


\section{STOP and DARE}

Lesson 3

\section{Lesson Overview}

Students will be given the opportunity to collaboratively write an essay using the essay planning and essay parts strategies. The linking word list will be explained in this lesson. The teacher will work individually with students assisting them in establishing personal goals for writing a good essay.

\section{Student Objectives}

The students will verbally state the part of the essay planning strategy STOP and the parts of a good essay as in DARE. The students will collaborative practice writing an essay using STOP and DARE. Using this essay and their previously written essay evaluated in Lesson One, the students will set a goal for writing essays.

\section{Materials}

STOP AND DARE MNEMONIC CHART (CHART), STOP AND DARE BRAINSTORMING SHEET (BRAINSTORM, LINKING/TRANSITION WORD SHEET, sample essays from Lessons One and Two, paper, pencils

\section{Set the Context for Student Learning}

Test the students to see if they remember the planning steps and essay parts. Ask the students if they've been thinking about what they've learned. Have each student tell you about a time they have used or thought about using STOP and DARE. 


\section{Develop the Strategy and Self-Regulation}

\section{Step One - Introduce Linking Words}

- Give each student a list of LINKING/TRANSITION WORDS.

"I'm going to show you some words that will help make your ideas go together. These probably aren't new words to you but you might not use them as often or as well as you could. Lets look at the list together."

"Let's think for a minute about transition or linking words. What does transition mean? How about linking? [Pause ... discuss their answer or ask where they might have heard those words before] Yes, transition means moving from one thing to another and linking means connecting things together. Why might we use words that we call transition or linking words? How might these types of words help make our essay better?"

- Ask the students to get the previously read sample essays from their folders.

"Okay, lets look at this essay we talked about before. Take a minute and look it over and see if you can find any transition or linking words in this essay. Use your list to help you. [Give them 1 minute to locate any transition words they can find] Okay, now, lets look at our list and see if we can find any different or better words that we could use instead of the ones used here. [Have the student explain their choices.] Transition words join the ideas we're discussing in our essay together. When we choose good transition words we are helping the reader follow our ideas and see how they connect to support our position. They are important! We want our ideas to make sense to the reader right?"

\section{Step Two - Criterion Setting}

- Ask student to take the CHECKLIST out of his/her folder. Explain that today you will write an essay together. This essay will be put on the checklist.

"Before we start on the essay, though, we want to set a goal for ourselves. Remember, we will use everything we have learned to help us. [Set the goal as having all 4 parts, plus more than 3 ideas] Do you think we'll be able to meet this goal? What do we need to remember? We also need to remember that longer essays are often better. Let's set a goal for the number of words we'll use. Let's look back at our graph of your first essay. [Set a goal for number of words based on their baseline essay.]" 
"Remember what we learned about transition or linking words. You can really improve your essay's quality and clarify your position if you use those words. I want us to try to use at least 3 transition words in the essay.

- Be sure that all the goals are appropriate based on the student's previous work.

\section{Step Three - Collaborative Practice}

- Explain that at least 2 essays will be planned and composed will together. Get out the essay topics, CHART, CUE SHEET, and BRAINSTORM sheets.

- Use the prompt.

"What is the first thing you have to say to yourself before you begin planning an essay?" They should answer with, "Plan my essay," or equivalent.

"Now we start the steps. What is Step 1?" (Students should say, "Suspend judgment.")

"How do we suspend judgment?" (Students should say, "Brainstorm ideas for and against the topic.") Get each student to brainstorm one idea. Write ideas on the BRAINSTORM sheet. Direct the students through CUE SHEET for this step. Make sure the student reads her/his own set sheet as you go.

"What is step 2?" (Students should say, "Take a side.") You lead discussion here, gaining consensus for the side you will take. If the student disagrees, you decide, and tell him/her he/she will get a chance to write their own essay next time, and can write and essay from the other point of view then.

"What is step 3?" (Students should say, "Organize ideas.") Again, lead the discussion, selecting strong ideas for the selected point of view and one or two arguments. Explain WHY they are stronger ideas. Direct the student to use the CUE SHEET. "Now that we have ideas we need to put them in order. What order do you think makes the best sense? [Let the student tell you an order first ] Why do you think this would be best? [Then you select best order, explaining why you are making that choice.] Remind them of the map analogy - deciding the order will help lead the reader to agree with your point of view. Also stress the logic behind the order (i.e., not jumping back and forth). Give an example.

"What is step 4?" (Students should say, "Plan more as you write.") Read cue sheet with DARE, and tell the student to keep the sheet in front of them as he/she composes. Refer to the "D" in DARE, then prompt him or her to create a topic sentence. Provide needed support. Continue generating sentences, referring to DARE and linking words.

\section{Step Four - Review Essay and Chart Performance}

- Have the student graph the essay's number of words, number of included essay elements, number of transition words and note the amount of time spent planning. 
- Compare these results to those of the initial baseline essay.

- Note that this essay is better than the previously written essay they examined in Lesson One. If needed, discuss whether the student's goal was appropriate (i.e., if they set too high goal, it should be lowered.) 


\section{Step Five - Verbal Rehearsal}

- Say, "We are going to memorize the CUE SHEET along with the planning steps and essay parts."

- To help the student memorize the planning steps and essay parts, teach him/her an exercise called rapid fire. This is called rapid fire because the steps are to be named as rapidly as possibly. Tell the student that if he/she needs to look at the CHART or CUE SHEET, she/he may; however, shouldn't rely on them too much because it will be put away after several rounds of rapid fire." (Allow student to paraphrase but be sure that intended meaning is maintained.)

- Do rapid fire with planning steps (STOP). If response is correct, make brief positive comment; if incorrect, prompt the student by pointing to the information. Correct wrong answers to ensure students learn the parts correctly.

- Do rapid fire without cues. If a student does not know a step, you provide it. Have the student repeat it back to you.

- After rapid fire, explain to students they must be able to name all the steps, cue sheet, and essay parts in an oral quiz. Give students time to rehearse.

- When a student indicates he/she has learned the steps, ask him/her to list them orally, including information from cue sheet. Describe information student omitted or named out of sequence.

- Tell student that writing the STOP \& DARE prompts at the top of the page can serve as reminder of the parts \& steps.

- Set goals for essay length, number of essay parts, transition words, and planning time for their next independent essay and note the goals on the graphing sheet.

\section{Wrap-Up}

Remind students that you will check next time to see if they can remember on their own the essay planning reminder (STOP) and the essay parts reminder (DARE). 


\section{STOP and DARE}

Lesson 4

\section{Lesson Overview}

Student will practice writing an essay independently using STOP and DARE. It is crucial that the teacher provide continuous feedback during the writing process.

\section{Student Objectives}

The student will verbally state the part of the essay planning strategy STOP and the parts of a good essay as in DARE. The student will independently practice writing an essay using STOP and DARE. Using his/her individual pretest essay, the students will set a goal for writing the essay.

\section{Materials}

STOP AND DARE MNEMONIC CHART (CHART), STOP AND DARE CUE SHEET (DIRECTIONS), STOP AND DARE BRAINSTORMING SHEET (BRAINSTORM), LINKING/TRANSITION WORD SHEET, paper, pencils

\section{Set the Context for Student Learning}

Using the rapid fire method, test the student to see if he/she remembers the planning steps and essay parts. Ask the student if he/she has been thinking about what he/she has learned. Have the student tell you about a time he/she used or thought about using STOP and DARE.

\section{Develop the Strategy and Self-Regulation}

\section{Step One - Criterion Setting}

- Review goals set at last session. They should be about twice or three times initial level. Be sure to include all four parts and "make sense." 


\section{Step Two - Independent Practice with Feedback}

- Give the student the essay topic and a BRAINSTORM sheet.

"I want you to use your CUE SHEET, list of LINKING/TRANSITION WORDS, BRAINSTORMING SHEET while to plan for and write this essay. Planning improves your writing. Remember how much better our essay we did together was compared to the one you did first? We planned a lot more, used our strategies, and transition words. Those things will improve your writing."

- Provide assistance only when the student skips a step or does it incorrectly. You may need to help if the order can lead to an illogical essay. Encourage him/her to use at least one word from the list of linking words if he/she fails to do so on his/her own.

\section{Step Three - Review Essay and Graph}

- After the student finishes, review his/her essay together. Have the student read their essay out loud; identify the parts (point out elaborations as well as the topic sentence, reasons, arguments, and conclusion, if there are any).

- If any parts are missing, discuss how and where they could be added.

- Have each student fill in CHECKLIST. Note that they reached goal (if did).

- Graph the results (length, essay parts, transition words) on the graphing sheet. Note the time spent planning.

- Discuss goal for next time: all seven essay parts, a longer essay and more transition words. Note goal on graphing sheet.

\section{Wrap-Up}

Remind students that you will check next time to see if they can remember on their own the essay planning reminder (STOP) and the essay parts reminder (DARE). 


\section{STOP and DARE}

Lesson 5

\section{Lesson Overview}

Student will learn to create his/her own planning sheet in this lesson. By this lesson the student should set goals for writing and composing essays independently.

\section{Student Objectives}

The student will verbally state the part of the essay planning strategy STOP and the parts of a good essay as in DARE. The student will create a planning sheet for writing the essay. The student will independently write an essay using STOP and DARE. The student will set a goal for writing an essay.

\section{Materials}

STOP AND DARE MNEMONIC CHART (CHART), STOP AND DARE CUE SHEET (DIRECTIONS), LINKING/TRANSITION WORD SHEET, sample essays from Lessons One and Two, paper, pencils

\section{Set the Context for Student Learning}

Using the rapid-fire method, test the student to see if he/she remembers the planning steps and essay parts. Ask the student if he/she has been thinking about what he/she learned. Have the student tell you about a time they have used or thought about using STOP and DARE. Discuss with the student that today they will learn a way to use the strategy without the BRAINSTORM sheet. Be sure to emphasize that by planning on their own, he/she can use STOP and DARE anytime he/she wants to write a good essay.

\section{Develop the Strategy and Self-Regulation}

\section{Step One - Create a Brainstorming Plan Sheet}

- Show student how to create his/her own planning brainstorming sheet by taking paper, writing STOP at top, drawing vertical line down the page, and writing DARE at the bottom. Model how to cross out letters in each word as he/she completes the steps.

- Briefly model a plan for an essay with a topic that was used during collaborative 
practice or independent practice. Do this quickly, but emphasize the steps that the student hasn't mastered yet, such as making order of ideas logical.

\section{Step 2 - Goal Setting}

- Review the goals set together at the end of the last meeting. Remind the student that using their strategy will make meeting his/her goal much easier. Note progress in previous graphs if needed.

Step 3 - Independent Practice with Feedback

- Give each student an essay topic.

"I'm going to ask you write an essay today. After looking at the topic I want you to begin by making your own brainstorming sheet like we just talked about. Once you've gone through all your STOP planning steps use a new sheet of paper to write your essay. You can use your LINKING/TRANSITION WORDS list if you need it. " [Be sure to check the student's plan! Provide assistance only when student skips a step or does it incorrectly.]

\section{Step 4 - Review Essays and Graph}

- Once completed, ask her/him to read it out loud. Ask him/her to identify the parts (point out elaborations as well as topic sentence, reasons, arguments, and conclusion, if there are any).

- If any parts are missing, discuss how and where they could be added.

- Graph essay parts, length, and transition words. Note the amount of time planning and writing. Note that he/she reached goal (if did).

\section{Wrap-Up}

Student should repeat this lesson - Lesson 5 - until he/she reach a criterion performance of all seven essay parts as in their pre-instruction essays. 


\title{
Appendix F
}

STOP \& DARE

Lesson 1

\section{Set the Context for Student Learning}

\author{
Introduce writing essays.
}

Step One - Describe and Discuss the Strategy: STOP

Discuss writing process with students, emphasizing planning

Introduce \& explain purpose of STOP AND DARE CHART

Introduce \& explain parts of STOP

\section{Step Two - Parts of an Essay}

Brainstorm parts of a good essay.

Introduce \& clarify terms: topic sentence, supporting ideas, argument(s), and conclusion

\section{Step Three - Essay Parts Reminder: DARE}

Give the sample essay to the student.

Student reads essay while teacher reads essay aloud.

Student identifies topic sentence, supporting ideas, argument(s), and conclusion

Ask for another example of each part for the same topic

Uncover the essay part reminder DARE chart \& read it aloud

Step Four - Chart Current Level of Performance

If time is running short proceed to step five and complete this step during the next session.

Hand out one of the pretest (baseline) essays.

Read essay aloud to student

Student identifies essay parts included in essay

Note which parts each student has and what is missing.

Graph number of essay parts and essay length

Explain purpose of graphing the information

Note that students may be able to make that part better the next time. Give examples

Explain the STOP AND DARE CHECKLIST.

Give the student a CHECKLIST

Student marks the number of essay parts written in their pretest.

$\square$ Explain the goal - to write better essays. Remind them that good essays have all STOP and DARE parts, and that good essays make sense.

Set a goal for the next time they write and note the goals on the graphing sheet (length \& essay parts).

\section{Step Five- Practice STOP and DARE}

Practice the mnemonic STOP.

Explain the purpose of memorizing mnemonic

$\square$ Turn over the CHART and ask the student to tell you the essay-planning reminder. Ask each student to write the reminder on paper. If students have trouble, turn the CHART over and allow them to look. Keep doing this until all students can tell you the reminder and explain each letter from memory.

$\square$ Practice the essay parts. Ask the student to explain the parts. Ask each student to write the reminder on paper. If students have trouble, turn the CHART back over and allow them to look. Help students as needed.

\section{Wrap-Up}

Give the student a reminder sheet to keep with them.

$\square$ Announce that there will be a non-graded test on essay planning \& essay parts in the beginning of the next session 


\section{STOP and DARE}

\section{Lesson 2}

\section{Set the Context for Student Learning}

$\square$ On a piece of paper and ask student to write down the essay planning reminder (STOP).

$\square$ Have student explain what each word/phrase means. Help as necessary.

$\square$ On a piece of paper and ask student to write down the essay parts reminder (DARE).

$\square$ Have student explain what each word/phrase means. Help as necessary.

\section{Step One - Identify Essay Parts and Elaborations}

Give the sample essay to the student.

$\square$ Read essay aloud while student reads to his/her self.

$\square$ Have student identify essay parts. Underline in essay as identified.

$\square$ Discuss elaboration. Locate in example essay.

\section{Step Two - Model the Strategy}

Model how to use the strategy to plan and write a good essay

Use CUE SHEET AND list of LINKING WORDS during modeling.

Model entire process - all steps including brainstorming sheet

$\square$ Elaborate on 2 or 3 ideas as you write, and try to revise something as you go

$\square$ When completed compliment yourself for the work you have done and then demonstrate graphing.

Mark the CHECKLIST for each part,

$\square$ Write down the number of ideas selected on the line under the column.

\section{Step Three - Rehearsal of STOP and DARE}

Review 4 steps - read STOP off chart using CUE SHEET

$\square$ Have student practice STOP

$\square$ Remind steps need to be memorized

$\square$ Review essay parts - read DARE off chart using CUE SHEET

Have student practice DARE

\section{Wrap-Up}

Remind student about un-graded quiz on the essay planning reminder (STOP) and the essay parts reminder (DARE) at next meeting. 


\section{STOP and DARE}

Lesson 3

\section{Set the Context for Student Learning}

$\square$ Test the students to see if they remember the planning steps and essay parts.

\section{Step One - Introduce Linking Words}

$\square$ Give student a list of LINKING/TRANSITION WORDS \& explain/discuss purpose of such words

$\square$ Have student get the previously read sample essays from folder.

$\square$ Find transition words in essays and discuss other/better word choices

\section{Step Two - Criterion Setting}

Have student take the CHECKLIST out of his/her folder.

Explain that today you will write an essay together.

Remind student about need for goals -4 essay parts, 3 or more ideas

Look at graph of baseline essay - use it to set goal of number of words

Remind student about transition words - set goal of using at least 3

\section{Step Three - Collaborative Practice}

$\square$ Get out the essay topics CUE SHEET, and BRAINSTORM sheets.

$\square$ Use the prompt.

$\square$ Ask student what should be done before writing essay - plan

$\square$ Go through each planning step

$\square$ Once planning is completed, refer to DARE \& transition words to write essay

\section{Step Four - Review Essay and Chart Performance}

Have the student fill in his/her CHECKSHEET.

$\square$ Note that this essay is better than the previously written essay they examined in Lesson One.

Graph number of words, number of included essay elements, number of transition words and note the amount of time spent planning.

Compare results to those of the initial baseline essay.

\section{Step Five - Verbal Rehearsal}

$\square$ Teach rehearsal exercise called rapid fire.

Do rapid fire with planning steps (STOP) using cues.

Do rapid fire without cues.

When student is ready, give oral quiz on STOP - correct as needed

Tell student that writing the STOP \& DARE prompts at the top of the page can serve as reminder of the parts \& steps.

$\square$ Set goals for essay length, number of essay parts, transition words, and planning time for next independent essay and note the goals on the graphing sheet.

\section{Wrap-Up}

$\square$ Remind students that you will check next time to see if they can remember on their own the essay planning reminder (STOP) and the essay parts reminder (DARE). 


\section{STOP \& DARE}

Lesson 4

\section{Set the Context for Student Learning}

$\square$ Use rapid fire method to test the on the planning steps and essay parts.

\section{Step One - Criterion Setting}

Review goals set at last session.

\section{Step Two - Independent Practice with Feedback}

Give the student the essay topic and a BRAINSTORM sheet.

Have student get CUE SHEET, list of LINKING/TRANSITION WORDS

$\square$ Remind student to use CUE SHEET, list of LINKING/TRANSITION WORDS, BRAINSTORMING SHEET plan for and write this essay.

$\square$ Remind student to plan before writing and to refer back to the plan

$\square$ Provide assistance only when the student skips a step or does it incorrectly.

\section{Step Three - Review Essay and Graph}

Review completed essay together.

$\square$ Identify the essay parts -point out elaborations as well as the topic sentence, reasons, arguments, and conclusion, if there are any.

$\square$ If any parts are missing, discuss how and where they could be added.

Have each student fill in CHECKLIST. Note that they reached goal (if did).

$\square$ Graph the results (length, essay parts, transition words) on the graphing sheet. Note the time spent planning.

Discuss goal for next time: all four essay parts, a longer essay and more transition words. Note goal on graphing sheet.

\section{Wrap-Up}

$\square$ Remind student that there will be a quiz next time on the essay planning reminder (STOP) and the essay parts reminder (DARE). 


\section{STOP \& DARE \\ Lesson 5}

\section{Set the Context for Student Learning}

$\square$ Use fire method to test the student on the planning steps and essay parts

$\square$ Discuss with the student that today they will learn a way to use the strategy without the BRAINSTORM sheet.

\section{Step One - Create a Brainstorming Plan Sheet}

Show student how to create his/her own planning brainstorming sheet by taking paper, writing STOP at top, drawing vertical line down the page, and writing DARE at the bottom.

Model how to cross out letters in each word as he/she completes the steps.

$\square$ Briefly model a plan for an essay with a topic that was used during collaborative practice or independent practice.

\section{Step 2 - Goal Setting}

Review the goals set together at the end of the last meeting.

Remind the student that using their strategy will make meeting his/her goal much easier.

Note progress in previous graphs if needed.

Step 3 - Independent Practice with Feedback

Give each student essay topic.

$\square$ Explain that student will be writing an essay independently and making their own brainstorming sheet

Remind the student write STOP \& DARE reminder at top of page

$\square$ Remind student to use transition words and their importance

\section{Step 4 - Review Essays and Graph}

Read completed essay aloud.

$\square$ Have student identify the parts -point out elaborations as well as topic sentence, reasons, arguments, and conclusion, if there are any.

$\square$ If any parts are missing, discuss how and where they could be added.

$\square$ Have student fill in CHECKLIST.

$\square$ Graph essay parts, length, and transition words. Note the amount of time planning. Note that he/she reached goal (if did).

\section{Wrap Up}




\section{Appendix G} QuickTime ${ }^{T M}$ and a
TIFF (Uncompressed) decompressor
are needed to see this picture.

\section{and DARE}

\section{Suspend Judgment}

2. Take a side

3. Organize ideas
Consider each side before taking a position Brainstorm ideas for and against the topic When you can't think of more ideas, ask these questions:

(a) Did I list ideas for each side? If not, do this now

(b) Can I think of anything else? Try to write more ideas; and

(c) Another point I haven't considered yet is...

Read your ideas. Decide which side you believe in, or which side can be used to make the strongest argument. Put a "+" on the side that shows your position.

Choose ideas that are strong and decide how to organize them for your writing. To help you do this, look at the next three cues:

(a) Put a star next to the ideas you want to use. Choose at least 3 ideas.

(b) Choose at least 1 argument to refute, and

(c) Number your ideas in the order you will use them

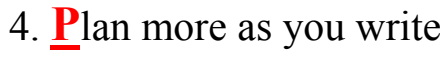
(DARE)
Develop your introductory paragraph

- What is the argument that I am trying to convince the reader to accept?

- Create an topic sentence

- What 3 supporting ideas am I going to present?

$\underline{\text { Add supporting ideas }}$

- at least 3 supporting ideas

- a paragraph for each idea

- How do they support your argument?

Reject possible arguments for the other side

- Why should my reader NOT support this argument?

End with a conclusion

- Summarize your argument \& supporting ideas 


\section{Appendix $\mathrm{H}$}

For continuing a line of reasoning/ Additional Support or Evidence:

consequently
clearly
then
furthermore
additionally
and

in addition

moreover

because

besides that

in the same way

also

To change the line of reasoning (contrast):

however

on the other hand

on the contrary

but

nonetheless

yet

in contrast

nevertheless

still

\section{Similarity:}

also

in the same way

just as

likewise

similarly

For opening a paragraph initially or for general use:

admittedly

assuredly

certainly

to be sure

granted

true

no doubt

nobody denies

undoubtedly

unquestionably

obviously

generally speaking

of course

in general

at this level

in this situation

Example:

for example

for instance

namely

specifically

to illustrate

For the final points of a paragraph or essay:

finally

lastly 
Transitional chains, to use in separating sections of a paragraph which is arranged chronologically:

first... second... third...

generally... furthermore... finally

in the first place... also... lastly

in the first place... pursuing this further... finally

to be sure... additionally... lastly

in the first place... just in the same way... finally

basically... similarly... as well

To signal conclusion/summary:

therefore

this

hence

in final analysis

in conclusion

in final consideration

finally

To restate a point within a paragraph in another way or in a more exacting way:

in other words

point in fact

specifically

$\underline{\text { Sequence or time }}$

after

afterwards

as soon as

at first

at last

before

before long

finally

Cause and Effect

accordingly

consequently

hence

so

therefore

thus indeed

in brief

on the whole

thus

in sum

in summary first... second... third

in the first place

in the meantime

later

meanwhile

next

soon

then 
Appendix I

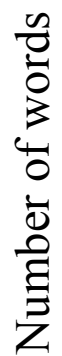

QuickTime $^{\mathrm{TM}}$ and a decompressor are needed to see this picture. 
QuickTime $^{\mathrm{TM}}$ and a
decompressor are needed to see this picture. 
Appendix $\mathbf{J}$

QuickTime $^{\mathrm{TM}}$ and a

decompressor
are needed to see this picture. 
Appendix K

\section{Noah Baseline}

No, what would be the point? They would still get the same grades. If boy have a girlfriend then they would be more able to pay attention and study and get good grades.

\section{Noah Independent Performance}

Teenagers shouldn't be allowed to choose their own bedtimes on school nights. Teenagers may be tired or cranky. They might fail classes and not do work if they are sleepy. Teenagers may not get up on time and be late to school. They may stay out after curfew and drink, smoke, or do crack. They might get into trouble with the police.

First, kids might be tired and cranky. Kids would say, "but teenagers may stay out after their bed time. Kids would learn more responsibility." But most kids are not responsible. Some kids might choose the right bedtime, but parents might think they went to bed but they will probably just watch TV in their rooms.

Similarly, teenagers might fail classes and not do work because they are sleepy. If they fail classes then they will not get in a good college. They won't know stuff. They could not get the job they want. If they have a job they might be tired and not do the job or kill someone. They might hurt themselves or others if they drive. They lost their job and be a hobo.

Finally, teenagers might be later for school. If they are tired then they may fall asleep again and be late for school. If they choose their own bedtime then they might stay up all night and sleep in school and they wouldn't get anything done in class. That would be a problem if they snored then the whole class could be disrupted and get everyone off track and they could fail the class because they can't pay attention.

In conclusion, teenagers shouldn't be allowed to pick their own bedtimes on school nights because they might be crabby or tired. They could fall asleep in classes an not do work or disrupt people from there work. If they are tired and in a group they could fail everyone in the group or get them mad at them. They could be lat for school or classes. So that is why teenagers shouldn't be allowed to pick their own bed times on school nights. 


\section{Christian Baseline}

Yes, I think they should because they can talk to kids that are fans and tell them to do good in school and get good grades and go to college or whatever. Most kids just need somebody to look up to and need a roll model and maybe one day they can be some kid's roll model.

\section{Christian Independent Performance}

Being an only child could be boring. There are no other siblings to play with inside your home. To some people its okay to be an only child. They could possibly be babied or spoiled, but truthfully, it could get super boring, and if their mom and dad worked they would be alone. However, with another kid they would have someone to play with.

First, if you ask me, I think that no kid should be an only child for the reason of being bored. But if someone has a little brother or sister they can look after it could teach them just a little bit of responsibility. And since they're the oldest they would have a brother or sister that will look up to them.

Also, if your close with your brother or sister you can talk to them and tell them things and teach them how to behave and have good manners. You guys could play video games or even watch TV together, well find some way to bond with each other. You could learn things from each other.

Some kids might not want younger siblings because they can be nerve wracking or annoying. They can also be brats and tell on you or get you into trouble a lot. Yes, all that's true but it's only for a short time.

Lastly, younger brothers and sisters are good family because they will always have your back, no matter what. Though they are younger they sill love their family and will protect you and your job is to protect them.

Finally, almost everybody needs someone younger or older that's there for them and cares. Younger brothers and sisters need other siblings so they can play and get along with someone like them. 